Article

\title{
Improving Efficiency in Congested Traffic Networks: Pareto-Improving Reservations through Agent-Based Timetabling
}

\author{
Luetian Sun and Rui Song *
}

check for updates

Citation: Sun, L.; Song, R. Improving Efficiency in Congested Traffic Networks: Pareto-Improving Reservations through Agent-Based Timetabling. Sustainability 2022, 14, 2211. https://doi.org/10.3390/ su14042211

Academic Editors: Efthimios Bothos, Panagiotis Georgakis, Babis Magoutas, Michiel de Bok and Matjaž Šraml

Received: 13 January 2022

Accepted: 11 February 2022

Published: 15 February 2022

Publisher's Note: MDPI stays neutral with regard to jurisdictional claims in published maps and institutional affiliations.

Copyright: (C) 2022 by the authors. Licensee MDPI, Basel, Switzerland. This article is an open access article distributed under the terms and conditions of the Creative Commons Attribution (CC BY) license (https:// creativecommons.org/licenses/by/ $4.0 /)$.
Key Laboratory of Transport Industry of Big Data Application Technologies for Comprehensive Transport, Beijing Jiaotong University, Beijing 100044, China; 16114187@bjtu.edu.cn

* Correspondence: rsong@bjtu.edu.cn

\begin{abstract}
In an urban transportation network, congestion occurs in the form of a queue behind a bottleneck. Many studies have considered a reservation-based optimization approach for queuing systems. To control the traffic density behind a bottleneck so that it does not exceed the link capacity, and to reduce the emissions and improve the sustainability of cities, we propose a new mobility service system to offer a Pareto-improving schedule for both the portion of agents making reservations and others with fixed departure time schedules. This reservation system takes the agents' (i.e., users or vehicles here) actual arrival and departure times from a conventional system without reservations as the preferred time windows at both the origins and destinations. Such a centralized mobility service system could maintain or improve the end-to-end traveling performance for all users. The proposed reservation and end-to-end timetabling problem is formulated as a multicommodity flow optimization problem in a discretized space-time network. We use a modified dynamic programming method for the reservation strategy on the space-time network and further adopt the alternative direction method of multiplier (ADMM) based on prime and dual theory to solve the large-scale instances. A comprehensive discussion is also provided regarding the technical challenges and potential solutions when operating such a system in a real-world setting.
\end{abstract}

Keywords: reservation scheduling; space-time network; ADMM algorithm

\section{Introduction}

Traffic congestion, which is characterized by slow speeds and long travel times, is actually an oversaturated queuing state on the road. The most important issue is to reduce the queues in the oversaturated areas, which will decrease agents' waiting times at the intermediate bottlenecks [1]. Mitigating a city's congestion is one of the primary goals of urban planners and transportation managers, as uncoordinated traffic demand patterns result in unreliable travel times and overall losses in terms of the system's operating efficiency [2]. Once congestion occurs, there will be increased emissions, which is not beneficial to the sustainability of cities. The real-world traffic system is extremely dynamic in its own right and typically weakly controllable, and the end-to-end travel times of road users are influenced by many factors, such as the congested state of the roads along with complex shockwave propagation between bottlenecks [3].

To reduce traffic congestion, traditional solution approaches incorporate information about the transportation network infrastructure into the model, e.g., adding road capacity constraints or using regulations to better manage and organize traffic through parking restrictions or freeway ramps. Providing travel information is also viewed as another important method that allows users to make better decisions by having information on hand ahead of time and avoiding unnecessary waiting times [4]. Furthermore, economic measures such as congestion pricing have been applied in many cities to encourage a shift in passengers' choice of mode and route to reduce the rush hour demand [5]. In a recent 
study, to avoid the use of road tolling schemes, a tradable credit scheme was conceived as a possible demand management tool to limit total travel distance [6]. In the closely related fields of passenger rail, air travel, hotel booking, car parking, and other resourceconstrained activities, a wide range of smart reservation systems have been designed to balance the excess booking demand and limited capacity [7]. Liu et al. (2015) [8] discussed the efficiency of a highway reservation system, proposing that an auction-based reservation system could improve efficiency based on a discussion on limited differentiation and two types of user heterogeneity. Levin et al. (2016) [9] proposed a reservation-based intersection control and represented the performances in several situations. Lamotte et al. (2017) [10] suggested that a reservation system for autonomous vehicles can reduce congestion once users with low cooperation take part. As long as there is a reasonable incentive system, users are willing to join a reservation system with high cooperation rates [11].

This research seeks to improve the operating efficiency (in terms of the variable discharging rate) in traffic bottlenecks through a joint reservation and scheduling scheme, even though most of the existing reservation-related studies (e.g., Levin and Boyles, 2015, [10,12]) have assumed fixed capacities in their underlying queuing model and have mainly focused on time slot reservations. Menelaous et al. (2017) [13] used temporal and spatial slots to make a reservation for every vehicle, which ensured that the flow did not exceed the capacity. Lioris et al. (2017) [14] proposed that the intersection capacity can be increased if demand flows in groups rather than one by one. Zhou et al. (2020) [15] proposed a mixedinteger linear programming method to solve a multi-periodic train timetabling problem by choosing appropriate arrival and departure times at each station, which improved the operating efficiency by minimizing total travel times. Essentially, we aim to provide an end-to-end timetable for individual vehicles so that not only the departure and arrival times, but also the intermediate link performance at key locations can be optimized [16,17].

Among a wide range of congestion-reduction approaches, Pareto-improving strategies are particularly attractive as they have the ability to increase the utility of each individual. For example, Daganzo and Garcia (2000) and Daganzo (2008) [18,19] considered variable tolls for commuters by addressing the distribution of the gains and losses across the population. A bi-objective optimization approach was used to reduce both vehicular congestion and emissions to achieve a Pareto-efficient control scheme. Guo and Yang (2010) and Chen and Yang (2012) [20,21] demonstrated a Pareto-improving congestion pricing solution in which every user could be better off compared with the situation without pricing. Barthelemy and Carletti (2017) [22] proposed a system to predict agents' behavior in a simulation and to determine the route for an individual based on a simple neural network. Chen et al. (2021) [23] proposed an improved learning-and-optimization methodology in which the convergence rate is exponential to address the congestion problems in CBD areas, and which needs less information compared with other optimization methods.

Regarding the reservation pattern (equity) choice, the essential elements are the equity and the Pareto improvements of the system. Recent research on the Boston school bus schedule focused on the equity of students' departure times, which involves many competing objectives in the planning process. However, the decisions may lead to some inequities; thus, a Pareto-improving scheme is significantly needed (Dimitris et al., 2019) [24]. Similar research by Massachusetts Institute of Technology (MIT) in 2019 on school bus departure times showed that, after implementing the proposed equity-based grouping strategy, adjusting the departure times benefited the majority of students. Tian et al. (2012) [25] proposed a ramp control scheme for morning peaks that improved the equity of the demand. Meng and Khoo (2010) [26] introduced a Pareto-improving strategy to ramp metering, which minimizes the total delay and maximizes the equity of the groups. Xiong and Zhang (2013) [27] presented a departure-time choice modeling framework based on road pricing and uncertainties, which involves Bayesian learning, knowledge updating, etc. Based on variable route massages, Xiong et al. (2016) [28] put forward a series of Bayesian processes to calibrate agents' behavior. Zou et al. (2016) [29] illustrated a behavior model dealing with agents' travel mode choices before trips based on Bayes' theorem and survey data. 
Xiong et al. (2019) [28] introduced an optimal incentive design system that provides optimal departure times and pre-trip routes for individuals. It should be noted that we do not intend to reveal underlying traveling preferences; therefore, the straightforward measurement of the in-vehicle travel-time window is used as the benchmark for quantifying the utility for each individual, even though other sophisticated means can be used, such as mobile internet usage data [30], to fully distinguish population segments.

As for the incentives for private cars to take part in the reservation system, these should be provided by transportation managers with incentives such as allowances and credit points. A recent experiment in the Huilongguan district in Beijing was significantly effective as agents were increasingly willing to use the reservation application system as the incentive increased. The results indicated that the total travel time was reduced for individuals who changed their departure times, which means that users will benefit from the application. On average, agents will save 20 min once they change their departure time, which will then save $90 \mathrm{~min}$ for the system on average. Furthermore, the traffic situation will be subsequently improved.

The remainder of this paper is organized as follows. In Section 2, by comparing our proposal with other reservation systems, we illustrate the major features of our reservation system. In Section 3, we propose an integer programming model to formulate the reservation scheduling problem for general networks based on a space-time network construct; then, the alternative direction method of multiplier (ADMM) algorithm is proposed to effectively solve the large-scale instances. Section 4 demonstrates the performance of our reservation scheduling model with a set of numerical experiments. Section 5 is a further discussion on the critical bottleneck performance improvements in a large-scale network. Finally, a systematic conclusion is proposed in Section 6, which also points out the current disadvantages and the next research step.

\section{Literature Review and Conceptual Illustration}

\subsection{Characteristics of Existing Reservation Systems}

The goal of optimizing urban transportation operations is to minimize the disutility of traveling, including in-vehicle waiting time, through the efficient use of vehicle and infrastructure resources. Table 1 specifically compares the key operating elements of reservation and conventional methods in various transportation modes. Compared with conventional congestion mitigation methods, the reservation approach takes advantage of: (i) advanced appointment by users; and (ii) a coordinated and synchronized schedule for using limited resources to maintain a balanced demand and supply at key locations and to operate the overall system efficiently.

There is a wide range of reservation systems with many different operating rules that improve different utility functions. Essentially, there are three major items in a user-oriented waiting utility function: (1) waiting at the origin before using the service; (2) the in-vehicle waiting time; and (3) schedule delay at the destination. Among these, the in-vehicle waiting time will result in queues behind bottlenecks, leading to traffic congestion. Our goal is to alleviate traffic congestion by reducing agents' in-vehicle waiting time.

Table 1. Comparison of transportation operating states before and after reservations.

\begin{tabular}{ccc}
\hline $\begin{array}{c}\text { Different Transportation } \\
\text { Modes }\end{array}$ & $\begin{array}{c}\text { Challenges in a Real-World } \\
\text { System without Reservations }\end{array}$ & Key Features and Benefits of Reservations \\
\hline Freeway reservations & $\begin{array}{c}\text { Users have random access to certain } \\
\text { freeways, which results in large } \\
\text { queuing costs. }\end{array}$ & $\begin{array}{c}\text { A slot reservation strategy eliminates queuing costs with a } \\
\text { significant cost reduction that could reach } \\
\text { approximately 50\%. }\end{array}$ \\
\hline Bike sharing [31] & $\begin{array}{c}\text { Users find no bikes at docking } \\
\text { stations and waste additional time } \\
\text { searching or waiting for bikes. }\end{array}$ & $\begin{array}{c}\text { A dynamic rebalancing strategy ensures that the bikes are } \\
\text { always available for reservations and orders, which reduces } \\
\text { the search time (i.e., disutility at origins). }\end{array}$ \\
\hline
\end{tabular}


Table 1. Cont.

\begin{tabular}{ccc}
\hline $\begin{array}{c}\text { Different Transportation } \\
\text { Modes }\end{array}$ & $\begin{array}{c}\text { Challenges in a Real-World } \\
\text { System without Reservations }\end{array}$ & Key Features and Benefits of Reservations \\
\hline $\begin{array}{c}\text { Taxis } \\
{[32]}\end{array}$ & $\begin{array}{c}\text { Taxi drivers need to spend } 1 / 3 \text { or } \\
1 / 4 \text { of their time traveling and } \\
\text { searching for passengers. }\end{array}$ & $\begin{array}{c}\text { A dispatch system chains multiple trips to form a } \\
\text { continuous route and offers the route to a taxi driver, which } \\
\text { reduces the drivers' idle time without revenue generation. }\end{array}$ \\
\hline Buses & $\begin{array}{c}\text { Users have to face random boarding } \\
\text { times at a bus station and delays } \\
\text { frequently happen at destinations. }\end{array}$ & $\begin{array}{c}\text { A customized bus schedule between passengers and } \\
\text { vehicles can reduce waiting times at bus stations and } \\
\text { arrival delays. }\end{array}$ \\
\hline Parking & $\begin{array}{c}\text { A driver may spend a lot of time } \\
\text { searching for, or waiting for, } \\
\text { available parking spots. }\end{array}$ & $\begin{array}{c}\text { Drivers use the short-term parking reservation system to } \\
\text { reserve parking spots. }\end{array}$ \\
\hline 34,35$]$ & &
\end{tabular}

There is also a wide range of traffic modes using reservation strategies and other optimization algorithms, from simple priority rules to much more sophisticated timetabling processes, which reduce the number of conflicts and reservations along the pathway. Recently, customized buses have increasingly appeared in our daily life, and reservations play a vital role in this. Tong et al. (2017) [36] proposed a mixed-integer programming model and a Lagrangian decomposition-based algorithm to solve the challenges for customized buses, including stop locations, routes, timetables, and passenger-to-vehicle assignments. Han et al. (2020) [33] presented a detailed individual reservation demand process that includes OD (origin and destination) vehicle routing based on agglomerative hierarchical clustering, ultimately creating several operating schemes for customized buses in Beijing.

Regarding another important set of infrastructure resources, parking reservations are designed to reduce users' search times and waiting times in parking areas. In an early study by Inaba et al. (2002) [37], drivers were assumed to be able to reserve parking spaces via the internet as soon as there is an available parking space. Hanif et al. (2011) [38] proposed a fully automated SMS (short message service) parking reservation service. Tsai and Chu (2011) [39] proposed an interesting pricing model that makes the reservation price equal to the value of the saved search time to encourage drivers to reserve parking resources. Kaspi et al. (2014) [40] considered a system with integrated parking reservations and one-way vehicle-sharing policies. Lei and Ouyang (2017) [41] improved the performance of an intelligent parking system, in which drivers compete for parking spaces and make online reservations. Latinopoulos et al. (2017) [42] presented a parking-and-charging reservation scheme to deal with the electricity demand and ensure that the capacity is adequate. Wang and Wang (2019) [34] illustrated a short-term parking reservation system with high-efficiency spatial-temporal flexibilities, in which a bi-level game-theoretical model was developed and optimized to provide systematic pricing scheme decisions. A continuum approximation method was then used to solve the challenge of dimensionality.

An intersection control-oriented reservation system aims to reduce the number of conflicts, while better managing complex resource-coupling constraints [43]. An important study along this line by Dresner and Stone (2004) [44] proposed a system that mitigated congestion and fully used the limited road resources at intersections, and they determined the benefits of the system using a customized simulator. Levin and Boyles (2015) [12] developed a tile-based intersection reservation policy in the broader context of dynamic traffic assignment. In the area of freeway reservations, Liu et al. (2015) [8] focused on how to relieve morning traffic congestion, considering the efficiency bounds of a system for accommodating reservation requests on a capacitated freeway network. Yu et al. (2019) [45] addressed the theoretical analysis of intersections and delay under intersection reservation control. They determined the service orders under each traffic condition after proposing a mixed-integer linear programming model that can dynamically form batches with optimal sizes. 
In emerging autonomous vehicle (AV) applications, Ma et al. (2017) [46] investigated an AV sharing and reservation system, where the controller will optimally arrange AV pickup and delivery schedules, and AV trip chains based on these requests. By adapting the space-time state modeling framework of Mahmoudi and Zhou (2016) [4], Ma et al. (2017) [46] constructed an elegant linear programming model to handle a large number of requests. Lamotte et al. (2017) [10] investigated the potential benefits of reservations for a bottleneck that is due to constant capacity and a certain market penetration rate of shared autonomous vehicles. Guo et al. (2017) [47] proposed a dynamic model for optimizing transit service switching for "smart transit" applications and for operating shared autonomous transit fleets. Levin and Boyles (2016) [9] partially highlighted and analyzed the changes in the outflow rate and backward wave speed using fundamental diagrams $[48,49]$ in response to different proportions of AVs, and they extended a carfollowing model [50] to a multiclass cell transmission model [51,52] to capture realistic road congestion in a simulation-based dynamic traffic assignment procedure. Recently, Wei et al. (2017) [53] also derived a fundamental diagram based on Newell's simplified car-following model [54] considering the different reaction times of human-operated and autonomous vehicles, and further proposed dynamic programming-based multivehicle longitudinal trajectory optimization models to minimize total travel costs (including time, energy, and emissions). Ouyang et al. (2021) [55] analyzed the influence of detour and waiting bounds on reservation-based carpooling services, and used closed-form formulas to explore business and regulatory strategies, the improved performance of which is well corroborated by agent-based simulations [56].

As for car-sharing reservations, Zografos et al. (2017) [57] developed an optimization framework for a one-way electric car-sharing system, proposing a methodology to decide on the relocations of vehicles, the movements of personnel and rental requests, and investigating different policies through optimization for serving demand requests. Molnar et al. (2019) [58] took profit, user satisfaction, and demand into consideration, proposing an optimization for simulation approach that allows long-term free-floating car-sharing reservations. Repoux et al. (2019) [59] introduced a proactive relocation policy that utilizes reservation information to implement a complete journey reservation policy, the performance of which is significantly improved by developing a Markovian model to estimate losses. Wang et al. (2021) [60] aimed to maximize the utilization level under the circumstance of a service failure rate below a preselected threshold value. They proposed a reservation and allocation model that considers the uncertainty in driver arrival/departure time and solved it using rule-based mixed-integer linear programming. Table 2 lists a number of studies closely related to the study in this paper.

Table 2. Standard related optimization studies on objective solution methods in reservation problems.

\begin{tabular}{|c|c|c|c|c|}
\hline Paper & Object to be Reserved & Objective/Utility & $\begin{array}{l}\text { Variables to Be } \\
\text { Controlled }\end{array}$ & Solution Algorithms \\
\hline $\begin{array}{l}\text { Tsai and Chu } \\
\text { (2011) [39] }\end{array}$ & Parking spots & Waiting time & Users' departure times & $\begin{array}{l}\text { Binomial pricing } \\
\text { method }\end{array}$ \\
\hline $\begin{array}{l}\text { Levin and Boyles } \\
\text { (2016) [61] }\end{array}$ & Freeway time slots & In-vehicle travel times & $\begin{array}{l}\text { Users' departure and } \\
\text { arrival times }\end{array}$ & $\begin{array}{l}\text { A multiclass cell } \\
\text { transmission model }\end{array}$ \\
\hline $\begin{array}{l}\text { Ma et al. } \\
\text { (2017) [46] }\end{array}$ & Freeway time slots & Vehicle miles traveled & $\begin{array}{c}\text { Users' departure times } \\
\text { and routes }\end{array}$ & $\begin{array}{c}\text { Linear integer } \\
\text { programming } \\
\text { formulation }\end{array}$ \\
\hline $\begin{array}{l}\text { Molnar and Homem } \\
\text { (2019) [58] }\end{array}$ & Long-term vehicle & $\begin{array}{l}\text { Reservation } \\
\text { performance }\end{array}$ & $\begin{array}{l}\text { Service level } \\
\text { parameters }\end{array}$ & $\begin{array}{l}\text { Iterated local search } \\
\text { (ILS) metaheuristic }\end{array}$ \\
\hline
\end{tabular}


Table 2. Cont.

\begin{tabular}{ccccc}
\hline Paper & Object to be Reserved & Objective/Utility & $\begin{array}{c}\text { Variables to Be } \\
\text { Controlled }\end{array}$ & Solution Algorithms \\
\hline Cheng et al. (2021) [62] & Lane & $\begin{array}{c}\text { Satisfy the target } \\
\text { travel time }\end{array}$ & The negative impact & $\begin{array}{c}\text { Nested artificial bee } \\
\text { colony and } \\
\text { Frank-Wolfe algorithm }\end{array}$ \\
\hline $\begin{array}{c}\text { Ouyang et al. } \\
\text { (2021) [55] }\end{array}$ & Carpooling service & $\begin{array}{c}\text { Reservation } \\
\text { performance }\end{array}$ & Travel distance & $\begin{array}{c}\text { An analytic model } \\
\text { and simulations }\end{array}$ \\
\hline Our paper & $\begin{array}{c}\text { Road resources at } \\
\text { traffic bottleneck with } \\
\text { variable outflow rate }\end{array}$ & $\begin{array}{c}\text { In-vehicle travel time } \\
\text { window defined by the } \\
\text { actual departure time } \\
\text { and arrival time }\end{array}$ & $\begin{array}{c}\text { Operating mode of } \\
\text { traffic bottleneck, } \\
\text { scheduled departure } \\
\text { times, stretch }\end{array}$ & $\begin{array}{c}\text { End-to-end travel } \\
\text { journey timetabling } \\
\text { and departure } \\
\text { time reservation }\end{array}$ \\
\hline
\end{tabular}

In our research, we are particularly interested in a Pareto-improving reservation scheme with a predetermined time window; that is, the proposed reservation action leads to a net welfare gain for each individual traveler without anyone becoming worse off in terms of their in-vehicle travel time window. This process is carried out in two stages, as shown in Figure 1. In the first stage, we identify the actual departure times (ADTs) and the actual arrival times (AATs) of users utilizing the available data sources, such as smartphones with embedded GPS sensors or on-board devices (OBDs) equipped inside cars. In the second stage, the road reservation system attempts to reschedule users' space-time trajectories based on two Pareto-improving conditions. Specifically, in the morning peak: (i) the reserved departure time (RDT) should be equal to or later than the ADT, and (ii) the reserved arrival time (RAT) should be earlier than or equal to the AAT (i.e., RDT $\geq$ ADT, $\mathrm{RAT} \leq \mathrm{AAT})$.

\subsection{Conceptual Illustration of a Discrete Space-Time Network with Tight Resource Constraints}

It is well known that the user equilibrium (UE) and system optimal (SO) principles are two typical traffic assignment rules. In this section, we use a small illustrative case to show how our proposed reservation approach offers a Pareto-improving solution that maintains or improves the utility for each individual road user. In particular, we consider a capacitated network with tight capacity constraints [63].

Figure 2 is adapted from a related study by Liu and Zhou (2016) [64], where node 1 is the origin and node 4 is the destination. Given the four paths in the network, let us consider two agents departing from node 1 . Table 3 compares the results of selfish routing, $\mathrm{SO}$, and reservations. In case (I) with selfish routing, if the first agent chooses the shortest path drawn using dashed lines in Figure 3, the second agent has to choose the long-distance path drawn using solid lines because of the tight capacity constraint. In this situation, as the noncooperative benchmark, the in-vehicle travel time of the second agent is 10 time units. In the SO case (II) with fixed departure times, the total travel time is 8 units. In case (III) for the proposed reservation scheme, when the second agent departs after the first one, both of them can choose the shortest path, and the arrival times of the two agents are no later than those in case (I). In short, case (III) is a Pareto-improving solution compared to case (I); that is, each agent's departure time is not earlier than and each agent's arrival time is not later than the corresponding values without reservations. We can determine that in a capacitated network, a reservation strategy will efficiently save users significant travel time. Figure 3 shows the route choice results and space-time trajectories in each case. 


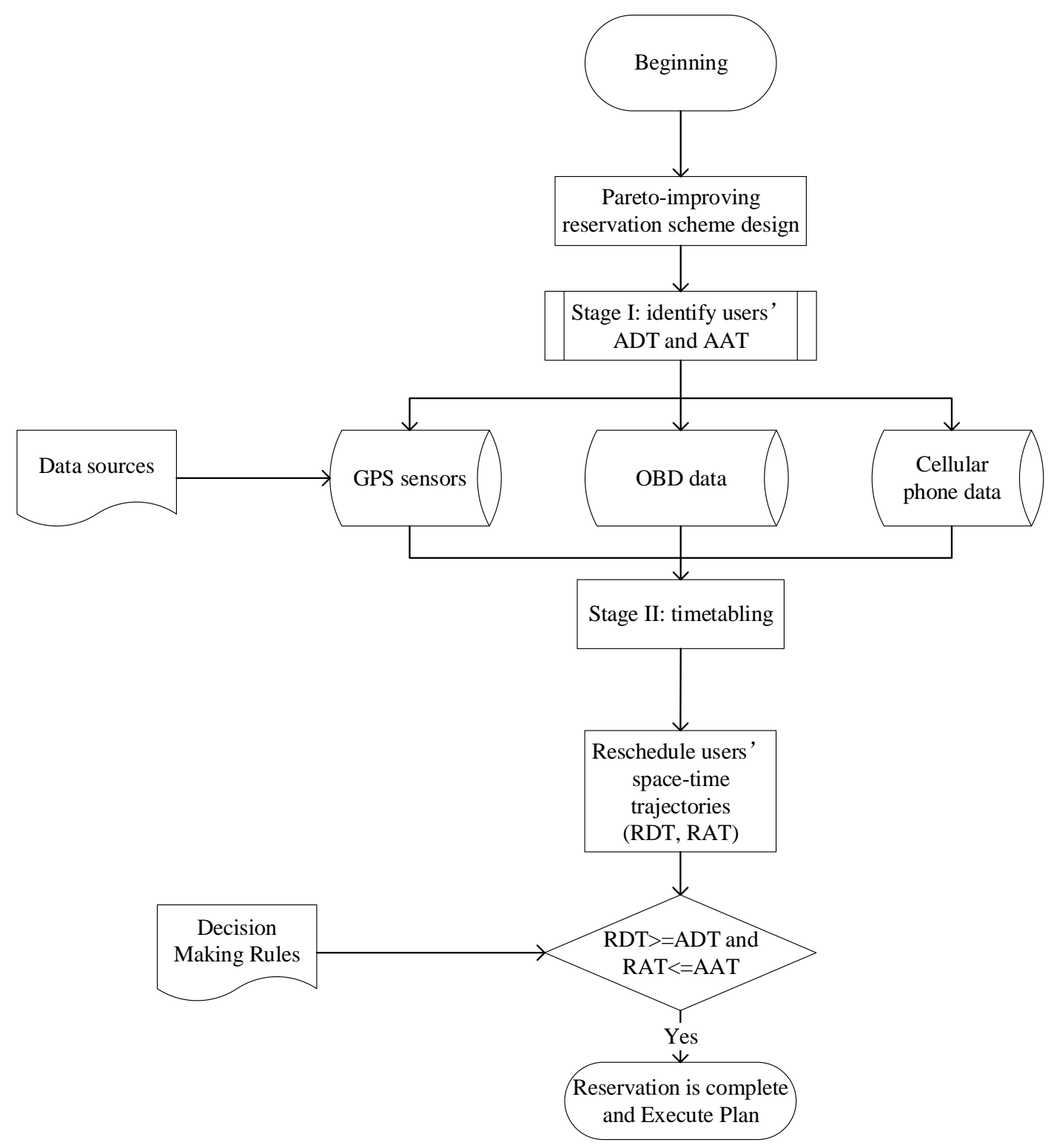

Figure 1. The process of the Pareto-improving reservation scheme.

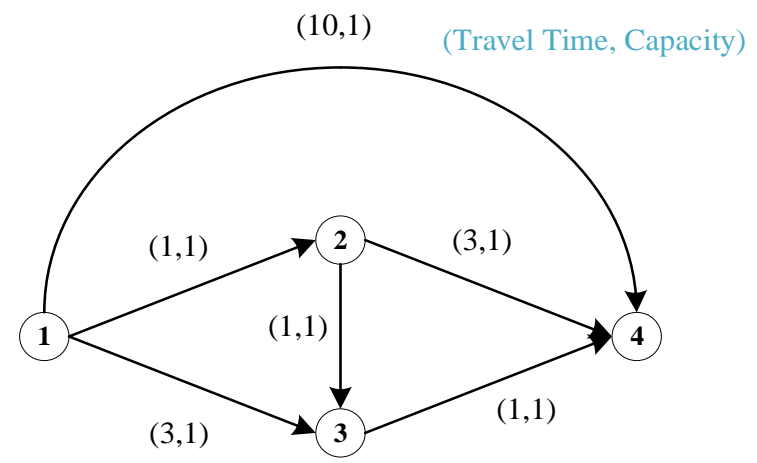

Figure 2. A four-node hypothetical network. There are two numbers $(\mathrm{T}, \mathrm{C})$ on each link, where $\mathrm{T}$ is the link travel time and $\mathrm{C}$ is the link capacity. 
Table 3. Comparison of the various aspects and solutions of UE, SO, and reservations.

\begin{tabular}{cccc}
\hline & $\begin{array}{c}\text { (I) Selfish Routing with } \\
\text { Fixed Departure Times }\end{array}$ & $\begin{array}{c}\text { (II) System Optimal with } \\
\text { Fixed Departure Times }\end{array}$ & $\begin{array}{c}\text { (III) Reservations with Flexible } \\
\text { Departure Times and Controllable } \\
\text { Traffic Operating States }\end{array}$ \\
\hline $\begin{array}{c}\text { Noncooperative case as } \\
\text { the benchmark }\end{array}$ & $\begin{array}{c}\text { Limited cooperation that } \\
\text { results in some users being } \\
\text { worse off }\end{array}$ & $\begin{array}{c}\text { Pareto-improving solution with } \\
\text { systematic cooperation }\end{array}$ \\
\hline $\begin{array}{c}\text { Agent } 1: \\
\text { departure time and } \\
\text { arrival time }\end{array}$ & {$[1,4]$} & {$[1,5]$} & {$[1,4]$} \\
\hline $\begin{array}{c}\text { Agent 2: } \\
\text { departure time and } \\
\text { arrival time }\end{array}$ & {$[1,11]$} & {$[1,5]$} & {$[2,5]$} \\
\hline $\begin{array}{c}\text { Total in-vehicle } \\
\text { travel time }\end{array}$ & 13 & 8 & 6 \\
\hline
\end{tabular}

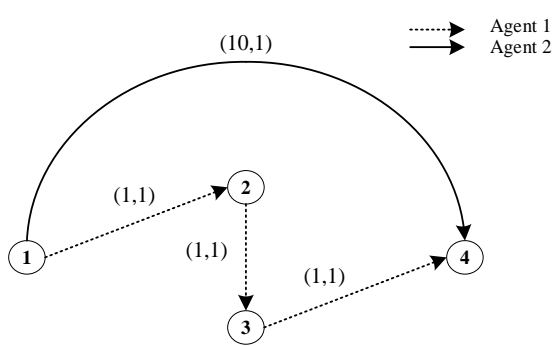

a. Case (I): Selfish routing with fixed departure times using a spatial network

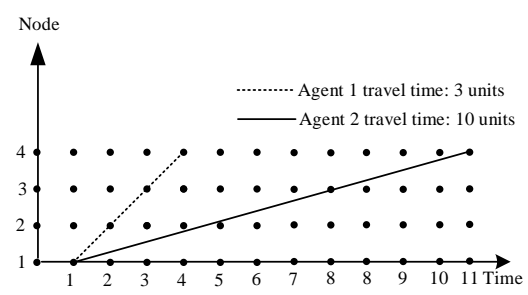

d. Case (I): Selfish routing with fixed departure times using a space-time network

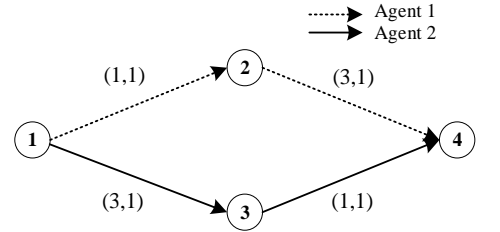

b. Case (II): System optimal with fixed departure times using a spatial network

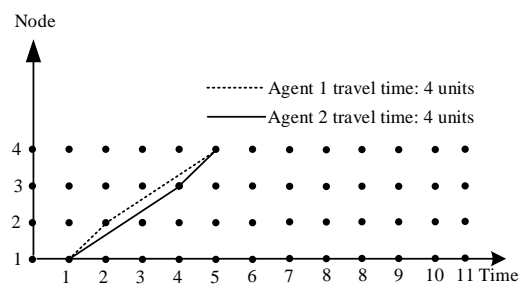

e. Case (II): System optimal with fixed departure times using a space-time network

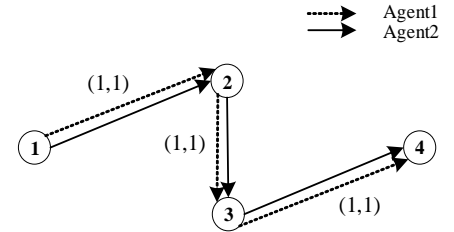

c. Case (III): Reservation with flexible departure times using a spatial network

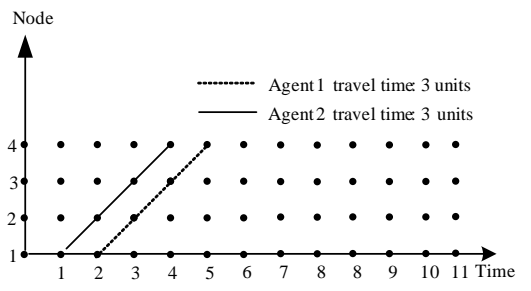

f. Case (III): Reservation with flexible departure times and controllable traffic operating states using a space-time network

Figure 3. Route choices in a physical network and trajectories using a space-time network for each case.

\section{Space-Time Network-Based Reservation Scheduling Model and Solution Methodology}

In this section, we propose a space-time network-based model to formulate the reservation scheduling problem for general networks. We then solve the reservation scheduling problem using an optimal solution algorithm. Here, we adopt a primal-dual method with which we dualize the variable capacity constraints into the objective function, and we generate the approximation to the primary problem by finding a solution to the dual problem. To increase the accuracy and decrease the number of calculations, an augmented Lagrangian function is formulated by adding a quadratic term, which is also called the alternating direction method of multipliers (ADMM). ADMM is a computational framework for solving optimization problems such as distributed convex optimization problems. Through decomposition and coordination, ADMM decomposes a large global problem into several local subproblems, and the global problem is then solved by coordinating the solutions of the subproblems. 


\subsection{Notation}

Table 4 lists the general indices, parameters, and variables used in the proposed model.

Table 4. Elements in the space-time network.

\begin{tabular}{|c|c|}
\hline Indices & Definition \\
\hline$i, j$ & Index of nodes, $(i, j) \in N$ \\
\hline$(i, j)$ & Index of links, $(i, j) \in L$ \\
\hline$a$ & Index of agents, $a \in A$ \\
\hline$t, t^{\prime}$ & Index of time intervals, $t, t^{\prime} \in T$ \\
\hline $\begin{array}{c}\left(t, t^{\prime}\right) \\
(i, t),\left(j, t^{\prime}\right)\end{array}$ & $\begin{array}{l}\text { Index of time arcs, with travel starting at } t \text { ending at } t^{\prime},\left(t, t^{\prime}\right) \in \varphi \\
\text { Index of space-time vertexes }(i, t),\left(j, t^{\prime}\right) \in E\end{array}$ \\
\hline$\left(i, j, t, t^{\prime}\right)$ & $\begin{array}{c}\text { Index of space-time travel arcs from node }(i, t) \text { to node }\left(j, t^{\prime}\right),\left(i, j, t, t^{\prime}\right) \in S \\
\text { if } i \text { equals } j,\left(i, i, t, t^{\prime}\right) \text { means waiting arc at node } i \text { from time } t \text { to } t^{\prime}\end{array}$ \\
\hline \multicolumn{2}{|l|}{ Sets } \\
\hline$N$ & Set of nodes $i$ in the physical network \\
\hline$T$ & Set of time intervals $t$ in the physical network \\
\hline$L$ & Set of links $(i, j)$ in the physical network \\
\hline$V$ & Set of vertexes $(i, t)$ in the space-time network \\
\hline$A$ & Set of agents $a$ in the space-time network \\
\hline$S$ & Set of travel arcs $\left(i, j, t, t^{\prime}\right)$ in the space-time network \\
\hline$\beta^{O}$ & Set of origin nodes \\
\hline$\beta^{D}$ & Set of destination nodes \\
\hline G & Space-time network \\
\hline \multicolumn{2}{|l|}{ Parameters } \\
\hline$O(a)$ & Origin node of agent $a$ \\
\hline$D(a)$ & Destination node of agent $a$ \\
\hline$c_{a}\left(i, j, t, t^{\prime}\right)$ & Space time arc costs of agent $a$ \\
\hline$E(a)$ & Expected arrival time of agent $a$ \\
\hline$\alpha^{n}$ & Step size of iteration $n$ \\
\hline $\operatorname{cap}(i, j)$ & Capacity of link $(i, j)$ \\
\hline$\lambda\left(i, j, t, t^{\prime}\right)$ & Lagrangian multiplier of link $(i, j)$ at time interval $\left(t, t^{\prime}\right)$ \\
\hline$\varepsilon$ & Maximum value of waiting cost at origin and destination nodes \\
\hline$t_{0}$ & The beginning time \\
\hline$T_{a}$ & The end time of agent $a$ \\
\hline$\xi_{i . j, t, t^{\prime}}$ & Slackness parameter in Lagrangian relaxation process \\
\hline$T T(i, j)$ & Travel time of link $(i, j)$ \\
\hline$\rho$ & ADMM parameter \\
\hline M & A maximum value in DP process \\
\hline$n e x t \_t$ & Next time period in DP process \\
\hline new_cost & New label cost in current time period \\
\hline node_predecessor & The last node connected to current node \\
\hline time_predecessor & The last time period connected to current time period \\
\hline \multicolumn{2}{|r|}{ 20. } \\
\hline$x_{a}\left(i, j, t, t^{\prime}\right)$ & $=1$ if traveling arc $\left(i, j, t, t^{\prime}\right)$ is used by agent $a$; otherwise,$=0$ \\
\hline Z & Objective variable, total cost \\
\hline
\end{tabular}

\subsection{Space-Time Network Design}

In the two stages of our reservation process, we first need to know all users' actual departure times and arrival times using available data sources. Then, a reservation model is built on a space-time network to reschedule the users' space-time trajectories, using the network timetabling method proposed by Meng and Zhou (2014) [65]. The recent work by Liao (2016) [66] can also be incorporated to model the duration choice in multistate super-networks, which can be viewed as expanded space-time networks. Although the problems that they solve using a space-time network are train rescheduling problems and individual activity travel scheduling problems, the space-time model is also suitable for highway reservation problems. The agents' trajectories can be distinctly depicted on a space-time diagram. The reservation-based model is also a mixed-integer programming (MIP) model, which is similar to the one used by $[65,66]$. With the help of virtual nodes, we 
use the space-time arcs between virtual nodes and origins, and the arcs between virtual nodes and destinations to represent the choices of reserved departure and arrival times in users' given time windows from the first stage.

Let us consider a physical network $D=(N, L)$, including a finite set of nodes $N$ and links $L$. Each link is denoted as a directed link $l=(i, j)$ between upstream node $i$ and downstream node $j$. Then, we need to build a space-time network framework for an agent-based reservation timetable problem. Let $G=(E, S)$ denote the space-time network with space-time vertex set $V$ and space-time arc set $S$, where the space-time vertex $(i, t)$ belongs to $V$ and the space-time arc $\left(i, j, t, t^{\prime}\right)$ belongs to $S$. For a given set of agents $A$, the parameter $c_{a}\left(i, j, t, t^{\prime}\right)$ specifies the costs for a space-time arc $\left(i, j, t, t^{\prime}\right)$ for agent $a$, including the waiting cost at the origin and destination, and travel time. Usually, agents prefer to wait at home rather than waiting on the way. Our goal is to generate a timetabling schedule with the least schedule delay for each agent. Thus, the objective of our model is:

$$
\min Z=\sum_{\left(a, i, j, t, t^{\prime}\right)} x_{a}\left(i, j, t, t^{\prime}\right) \times c_{a}\left(i, j, t, t^{\prime}\right)
$$

The flow balance constraint is as follows:

$$
\begin{gathered}
\sum_{j, t^{\prime}:\left(i, j, t, t^{\prime}\right) \in \beta^{O}(a)} x_{a}\left(i, j, t, t^{\prime}\right)=1 \forall a, i=O(a), t=t_{0} \\
\sum_{i, t:\left(i, j, t, t^{\prime}\right) \in \beta^{D}(a)} x_{a}\left(i, j, t, t^{\prime}\right)=1 \forall a, j=D(a), t=E(a) \\
\sum_{i, t:\left(i, j, t, t^{\prime}\right) \in S} x_{a}\left(i, j, t, t^{\prime}\right)-\sum_{j^{\prime}, t^{\prime \prime}:\left(j, j^{\prime}, t^{\prime}, t^{\prime \prime}\right) \in S} x_{a}\left(i, j, t, t^{\prime}\right)=0 \forall a,\left(j, t^{\prime}\right) \in \\
E /\left\{\left(O(a), t_{0}\right),\left(D(a), T_{a}\right)\right\}
\end{gathered}
$$

The number of agents at any time period cannot exceed the maximum value, so links are operating in the free flow mode. The relationship can be formulated as Equation (5):

$$
\sum_{a} x_{a}\left(i, j, t, t^{\prime}\right) \leq \operatorname{cap}(i, j), \forall t, t^{\prime} \in T
$$

Usually, agents prefer to wait at home rather than getting caught in traffic, so waiting costs at origins and destinations can be ignored compared with other space-time arc costs, as Equation (6) shows:

$$
c_{a}\left(i, i, t, t^{\prime}\right) \leq \varepsilon, i \epsilon\left\{\beta^{O}, \beta^{D}\right\}
$$

Our space-time model is a mixed-integer programming (MIP) model, and we would like to compare our proposed model with a related link-based system, the optimal dynamic traffic assignment (DTA) mathematical programming model proposed by Lasdon and Luo (1994) [67]. Their link-based model aims to find a system optimal routing solution with a fixed departure time based on a given exit function. Compared with this typical exit function-based DTA optimization model, our proposed agent-based model has the following unique features: (1) our agent-based reservation model provides a reservation solution for each user by embedding the complex end-to-end time window in the spacetime network construct; (2) our scheduling problem is modeled as a timetabling problem using a space-time network representation; and (3) the users' departure times are intended to be flexible within a given time window to offer a system optimal solution. A detailed comparison of the equations is listed in the last of Section 5. In future research, we need to further extend the model to consider the minimum expected disutility of path travel times, as studied in the paper by Huang and Gao (2012) [68].

\subsection{Solution Methodology}

To solve the MIP model for the reservation and scheduling problem, we consider the use of standard optimization solvers and customized heuristic methods for large instances, especially those with discretized network structures. As our formulation has possible problematic decomposition features, a Lagrangian relaxation heuristic used in the study by 
Hoitomt and Luh (1988) [69] can be adapted to solve the resource-distribution problem via a constrained integer programming formulation.

\subsection{Space-Time-Based Two-Dimensional Dynamic Programming (DP) Methodology}

Compared with the enumeration method, the dynamic programming methodology saves a lot of computational time in spite of it costing storage memory. [70] proposed a time-dependent dynamic programming for space-time network system design, which uses a scan eligible list to save the space-time vertex to the date label cost in order to save searching space. In the reservation methodology, agents are expected to wait at origins and destinations so that the origin or destination vertex will always be in a scan eligible list. Hence, we use a modified DP method for reservations.

Given the agents' preferred departure and arrival times, we make the shortest spacetime path [71], which allow agents to wait at origins and destinations. The two-dimension DP method is designed as per the table below. We use accessible flag $F\left(O^{a}, t_{d}^{a}\right)$ instead of a scan eligible list; space-time arcs with the accessible flag are in the searching queue. As each agent's preferred arrival time is given as a parameter in the following DP process, the agent's related departure time (the solution) is searched based on the arrival time. That is, the DP process can ensure that the agents will arrive on time.

The detailed DP process is as followed:

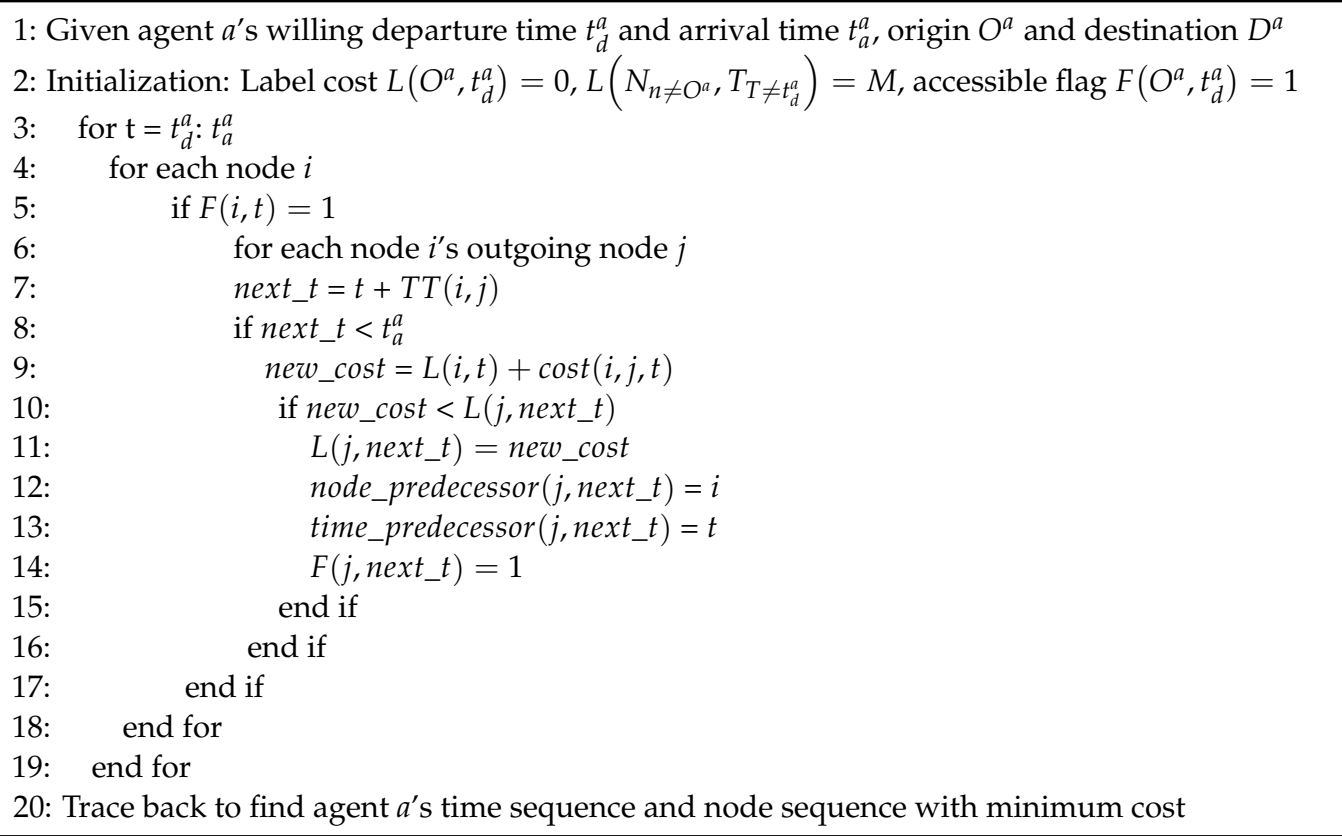

\subsection{Augmented Lagrangian Relaxation Solution Framework for a General Network}

The constraint to be relaxed is usually the most complicated one, and so we dualize the capacity constraint (Equation (5)). We introduce a nonnegative Lagrangian multiplier $\lambda_{i, j, t, t^{\prime}}$ to dualize the capacity constraint as a penalty in the objective function and use $\rho_{i, j, t, t^{\prime}}$ as the quadratic penalty. As the capacity constraint is an inequality constraint, we add a slackness term $\xi_{i . j, t, t t^{\prime}}$ in case we violate the equality constraint while calculating the ADMM. The augmented Lagrangian equation with an ADMM penalty term is shown in Equation (7):

$$
\begin{gathered}
\min L=\sum_{\left(i, j, t, t^{\prime}\right) \in S} \sum_{a} c_{a}\left(i, j, t, t^{\prime}\right) \times x_{a}\left(i, j, t, t^{\prime}\right)+\lambda_{i, j, t, t^{\prime}} \times\left(\sum_{a} x_{a}\left(i, j, t, t^{\prime}\right)-\operatorname{cap}(i, j)+\xi_{i . j, t, t^{\prime}}\right)+ \\
\frac{\rho_{i, j, t, t^{\prime}}}{2} \times\left(\sum_{a} x_{a}\left(i, j, t, t^{\prime}\right)-\operatorname{cap}(i, j)+\xi_{i . j, t, t^{\prime}}\right)^{2}, \forall t, t^{\prime} \in T
\end{gathered}
$$

which is subject to constraints (2), (3), (4) and (6).

It is important to recognize that the primary problem can be viewed as a combination of several problems with standard and practically efficient solution algorithms. The master 
problem is viewed as a multicommodity flow optimization problem, while the subproblems are the shortest-path problems with waiting arcs at origins and destinations. Below is the ADMM solution procedure. It is noteworthy that the ADMM term is quadratic, and the quadratic term is a quadratic component of $x_{a}\left(i, j, t, t^{\prime}\right)$. In our integer programming, the value of $x_{a}\left(i, j, t, t^{\prime}\right)$ is either 1 or 0 , whose quadratic component is itself, that is:

$$
x_{a}\left(i, j, t, t^{\prime}\right)^{2}=x_{a}\left(i, j, t, t^{\prime}\right) x_{a}\left(i, j, t, t^{\prime}\right) \epsilon\{0,1\}
$$

This means the quadratic programming can be linearized in this way.

The detailed ADMM process is as followed:

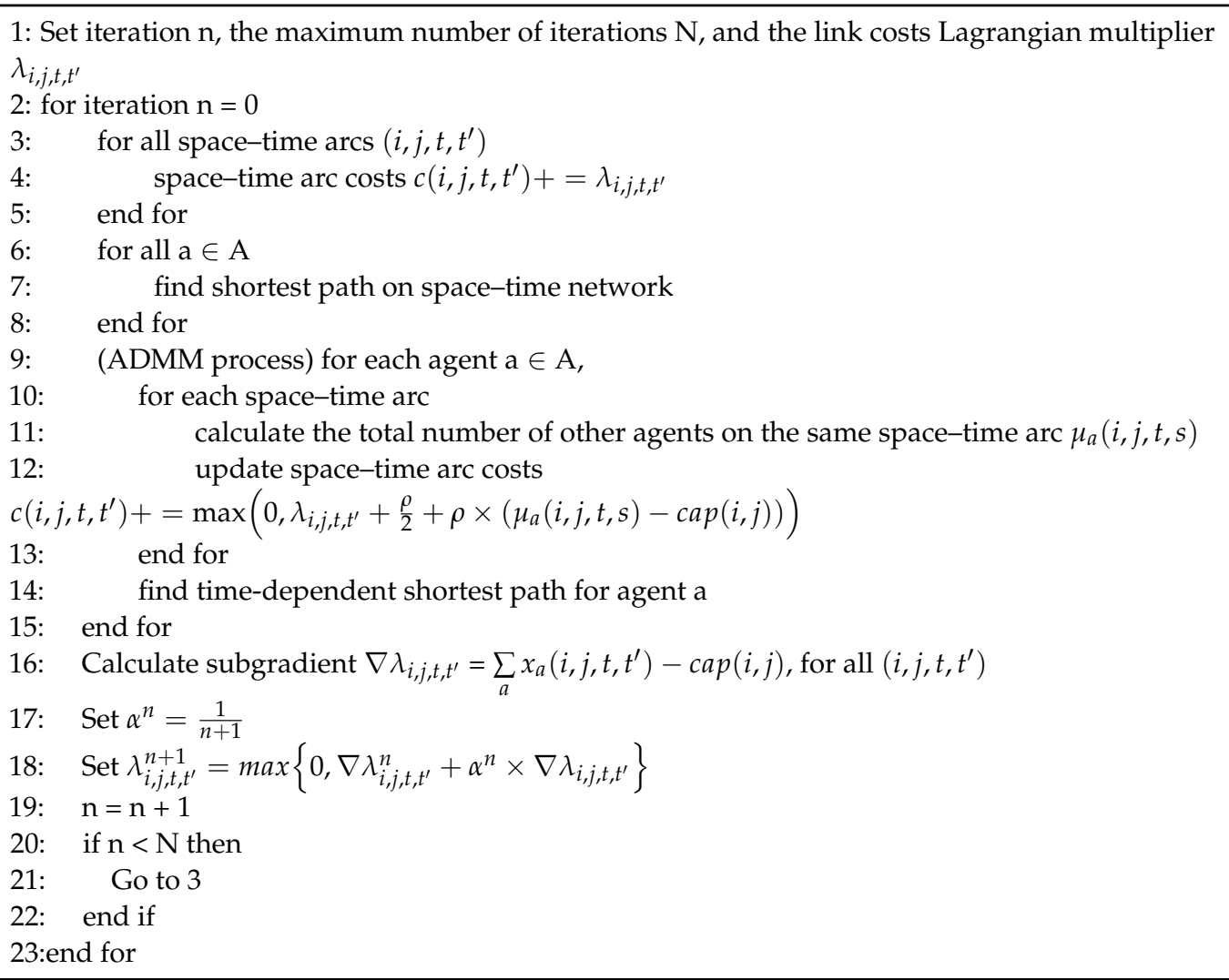

\section{Numerical Experiments}

In this section, we evaluate the performance of our reservation scheduling model under different settings and demonstrate the properties of the solutions. First, an agentbased case is solved by GAMS using the ADMM algorithm, which can effectively avoid the symmetry compared with a Lagrangian relaxation algorithm. A large-scale case with 1,260,907 agents is optimized on a desktop with an Intel i7 $2.5 \mathrm{GHz}$ CPU and 8 GB RAM.

\subsection{Illustrative Small Network Using Standard Optimization Solver}

In this case with a merging point, we use a hypothetical network at a merging point, as shown in Figure 4, which includes 4 nodes, 3 links, and the 2 OD pairs $(1,4)$ and $(2,4)$. We hypothesize that the waiting costs at immediate node 3 are 1 , which is equal to the travel costs at each link, while the waiting costs at the origin node are 0.5.

The reservation scheduling model is solved by the GAMS commercial solver. Figure 5a shows the case without reservations, where the lines in different colors indicate different agents' trajectories, and the optimal user trajectories are shown in Figure 5b. Table 5 shows the contrastive data in the two different situations that were above. As a result, the total travel costs are decreased as agents can wait at origins, saving a total of 17.7 in travel costs in this case. 


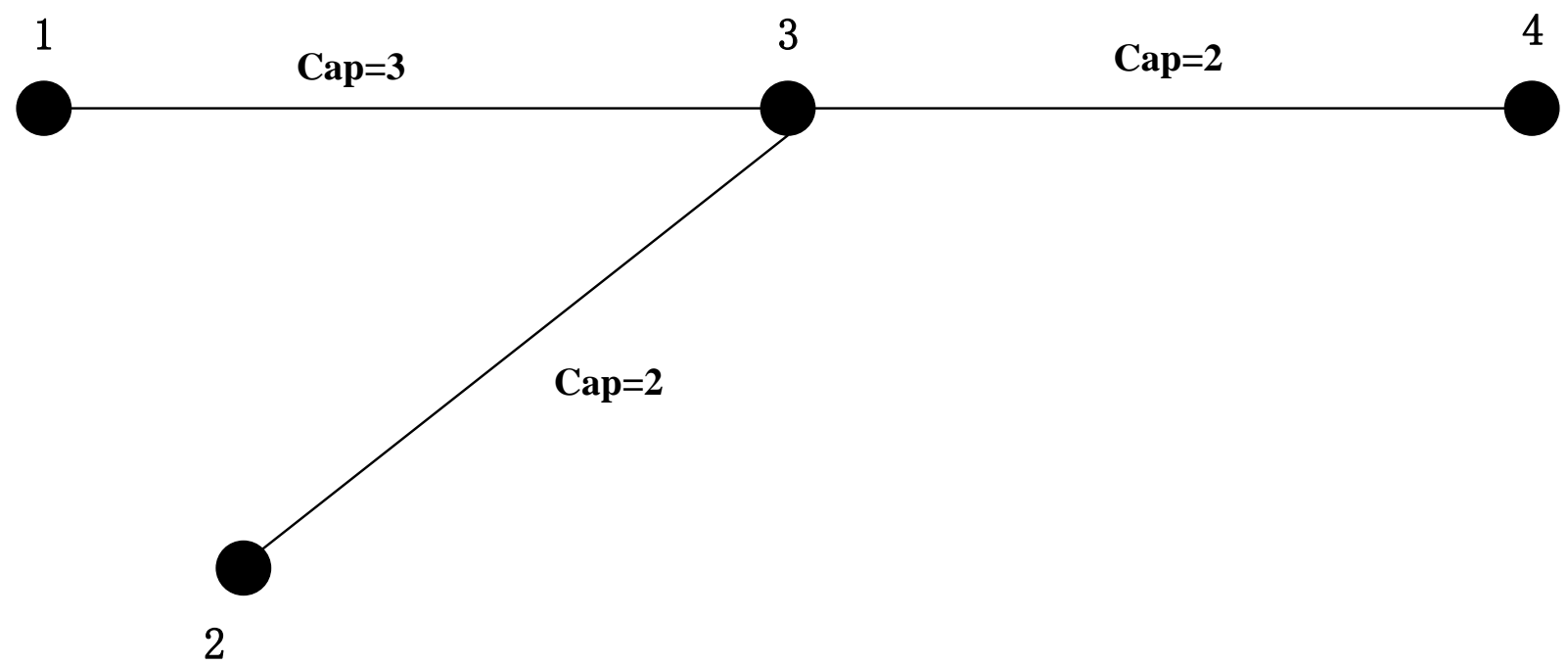

Figure 4. A hypothetical four-node network.
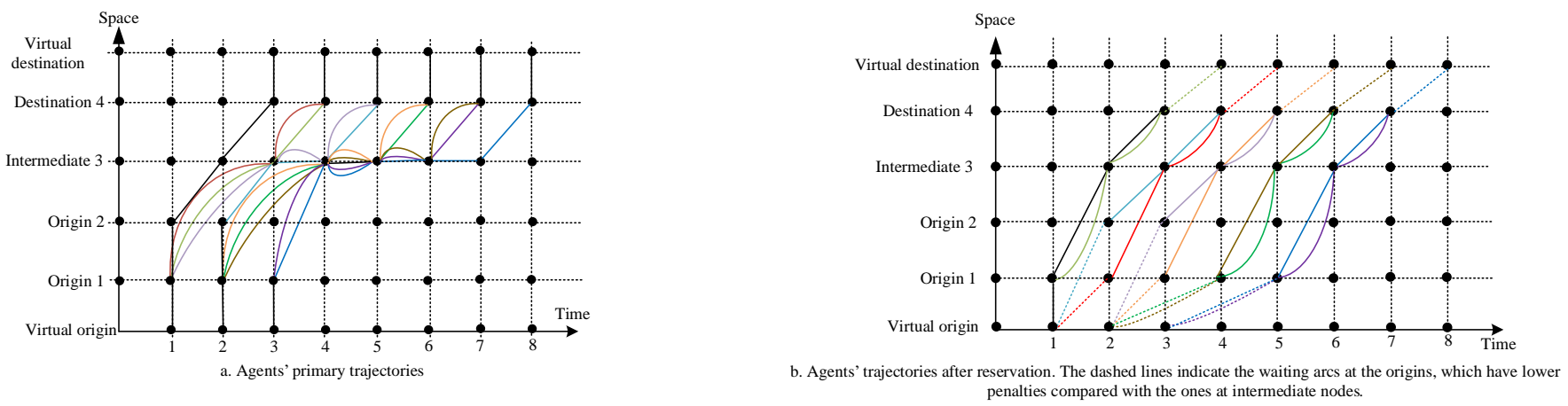

Figure 5. Comparison of agents' trajectories with and without reservations.

Table 5. Comparison of cases before and after reservations.

\begin{tabular}{ccccc}
\hline Agent Id & Original Path & Costs & Path with Reservation & Costs \\
\hline 1 & $2 ; 3 ; 4$ & 2 & $2 ; 3 ; 4$ & 2 \\
2 & $1 ; 3 ; 4$ & 2 & $1 ; 3 ; 4$ & 2 \\
3 & $1 ; 3 ; 4$ & 2 & $1 ; 3 ; 4$ & 2 \\
4 & $1 ; 3 ; 3 ; 4$ & 3 & $1 ; 1 ; 3 ; 4$ & 2.5 \\
5 & $2 ; 3 ; 3 ; 4$ & 3 & $2 ; 2 ; 3 ; 4$ & 2.5 \\
6 & $1 ; 3 ; 3 ; 4$ & 3 & $1 ; 1 ; 3 ; 4$ & 2.5 \\
7 & $1 ; 3 ; 3 ; 4$ & 3 & $1 ; 1 ; 3 ; 4$ & 2.5 \\
8 & $1 ; 3 ; 3 ; 3 ; 4$ & 4 & $1 ; 1 ; 1 ; 3 ; 4$ & 3 \\
9 & $1 ; 3 ; 3 ; 3 ; 4$ & 4 & $1 ; 1 ; 1 ; 3 ; 4$ & 3 \\
10 & $1 ; 3 ; 3 ; 3 ; 3 ; 4$ & 5 & $1 ; 1 ; 1 ; 1 ; 3 ; 4$ & 3.5 \\
& & Total $=31$ & & Total = 25.5 \\
\hline
\end{tabular}

\subsection{Large-Scale Experiment}

A large-scale numerical experiment is conducted on the Chicago sketch network with 547 nodes and 2177 links, shown in Figure 6. The total number of agents is approximately 1,260,907 for a $2 \mathrm{~h}$ demand loading period (morning peaks) at 7:00-9:00. 


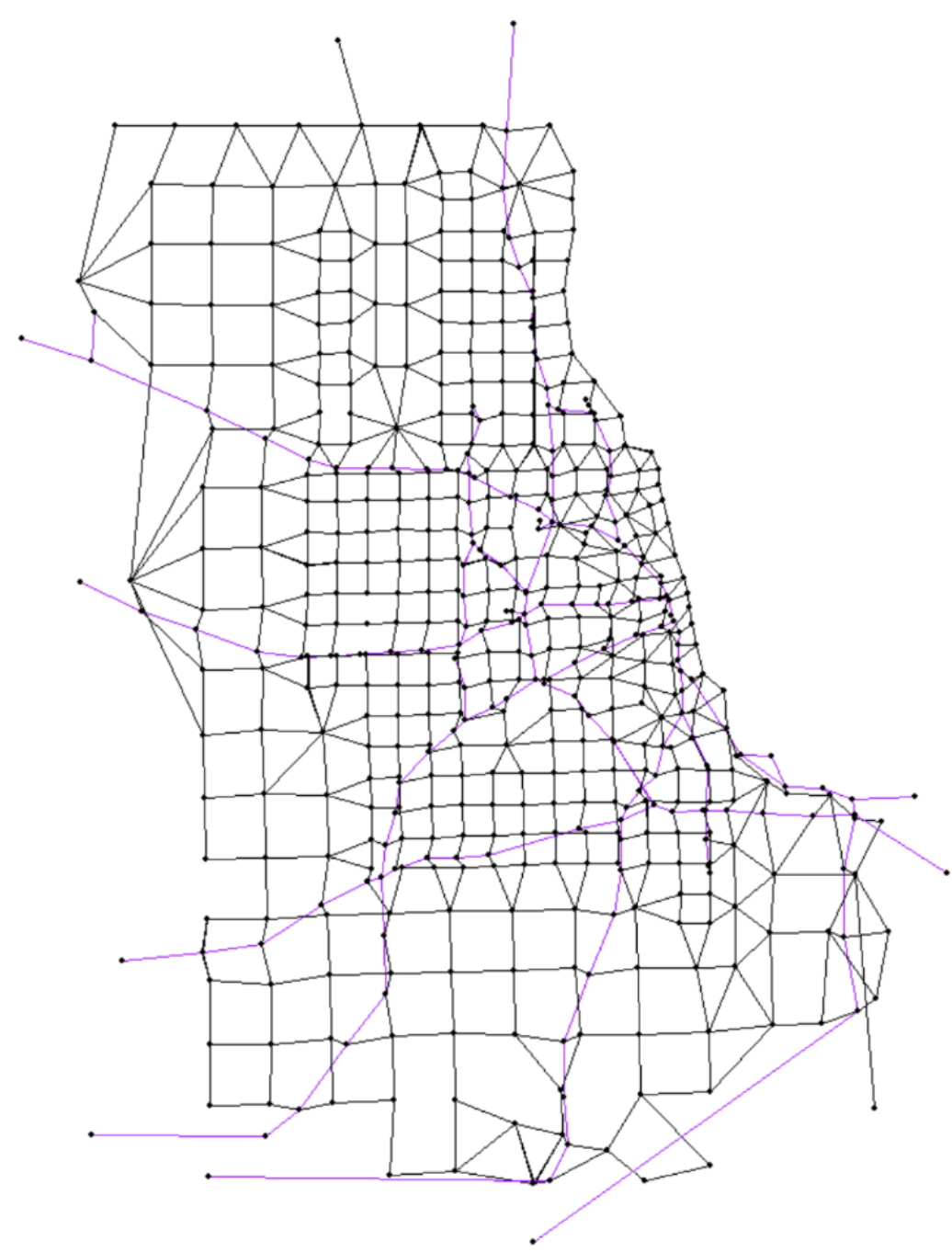

Figure 6. Chicago sketch transportation network with 547 nodes and 2177 links.

Regarding the input files, the file named "agent.csv" contains 743 major ODs, with each OD will generating approximately 170 agents on average. The "road_link.csv" contains from node, to node, link capacity, etc., which shows the details of the network. As the network contains many nodes and links, which cost a lot of computational time, we first generate node sequences of each OD pair as the agents' likely path choices in DTALite, and then use these "sub-networks" to conduct space-time DP so that the searching scale of the DP in each ADMM cycle will not be too wide. The "sub-networks" are shown in Figure 7. As a result, the total number of sub-networks is 753. The computational time for 1 iteration of ADMM is approximately $60 \mathrm{~s}$ in the computational environment, which is an Intel i7 $2.5 \mathrm{GHz}$ CPU and $8 \mathrm{~GB}$ RAM. The related dataset and $\mathrm{C}++$ code are available at the website https://github.com/SunLvetianBJTU/ADMM_space_time_trajectory (accessed on 31 December 2021), which is based on the space-time DP and ADMM algorithm. Consequently, it takes approximately 8-9 iterations for the algorithm to reach the optimal solution. The typical agents' trajectories are shown in Figure 8, and the time unit in the horizontal axis is $4 \mathrm{~min}$. The blue solid lines of the trajectories are waiting arcs.

The output file "output_agent.csv" includes the agents' trajectories, which consist of "node_sequence," "link_sequence," and "time_sequence." Table 6 shows 20 agents' trajectories with node sequences, time sequences, reserved node sequences, and reserved time sequences. The repeating node numbers in "path_node_sequence" are agents' waiting arcs. The comparison of link performance before and after reservation is shown in Table 7. 


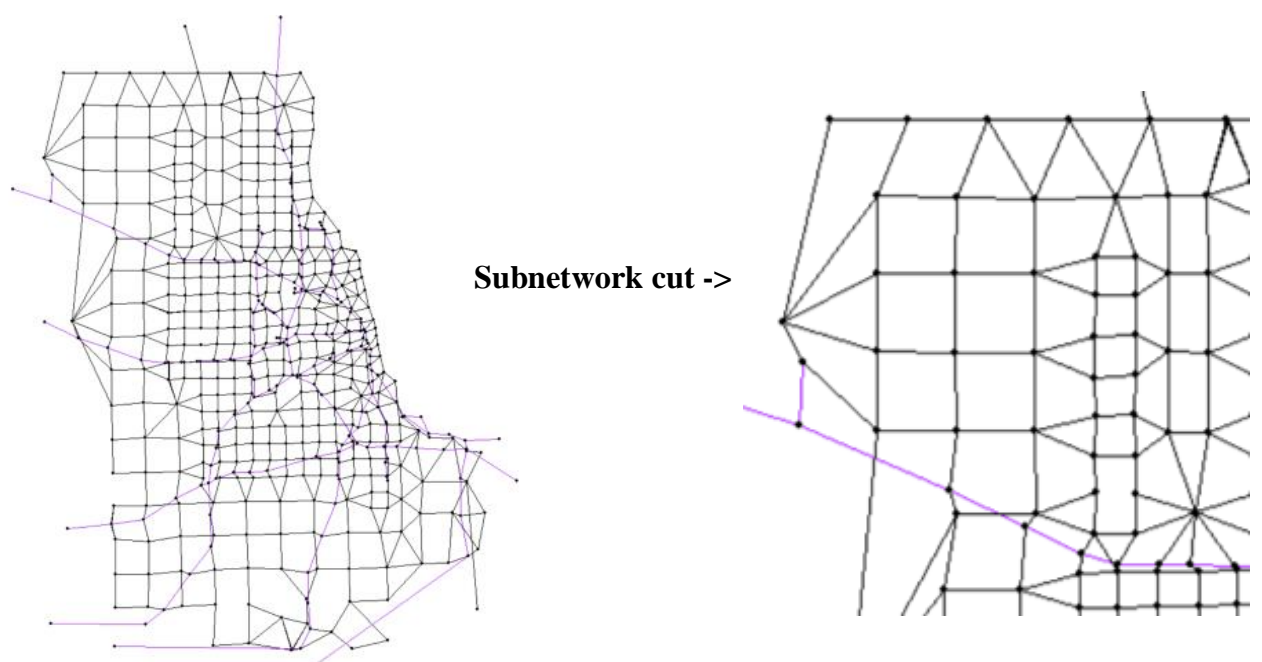

Figure 7. Network simplified.

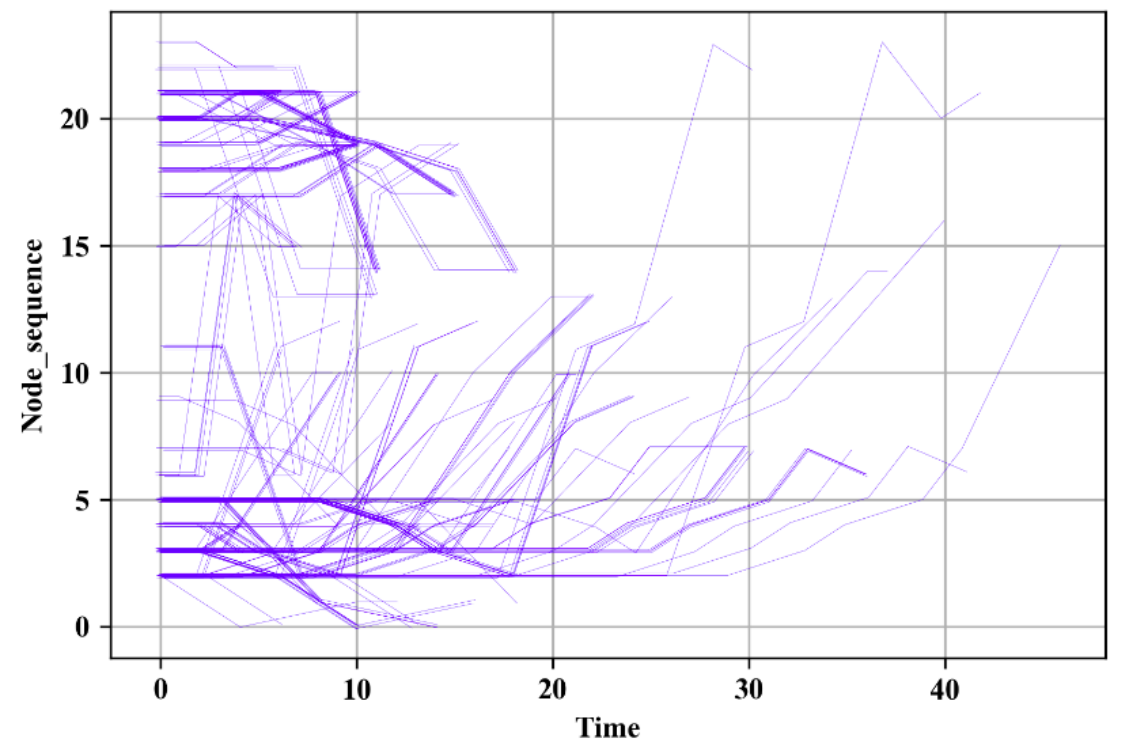

Figure 8. Agent space-time trajectories.

Table 6. Agent trajectories in an output file.

\begin{tabular}{|c|c|c|c|c|}
\hline Agent Id & Path Node Sequence & $\begin{array}{c}\text { Path Node Sequence } \\
\text { Reserved }\end{array}$ & Path Time Sequence & $\begin{array}{c}\text { Path Time Sequence } \\
\text { Reserved }\end{array}$ \\
\hline 134 & $1 ; 72 ; 381 ;$ & $1 ; 1 ; 72 ; 381$ & $530.10 ; 530.23 ; 530.40$ & $\begin{array}{c}530.10 ; 530.20 ; 530.30 \\
530.40 ;\end{array}$ \\
\hline 157 & $68 ; 159 ; 188 ; 1 ;$ & $68 ; 68 ; 159 ; 188 ; 1 ;$ & $\begin{array}{c}530.20 ; 530.35 ; 530.72 \\
530.80\end{array}$ & $\begin{array}{c}530.20 ; 530.30 ; 530.45 \\
530.62 ; 530.80\end{array}$ \\
\hline 189 & $1 ; 72 ; 381 ;$ & $1 ; 72 ; 381 ; 381 ;$ & $530.20 ; 530.36 ; 530.50$ & $\begin{array}{c}530.20 ; 530.30 ; 530.40 \\
530.50\end{array}$ \\
\hline 256 & $470 ; 356 ; 299 ; 521 ;$ & $470 ; 470 ; 356 ; 299 ; 521 ;$ & $\begin{array}{c}530.30 ; 530.43 ; 530.81 \\
530.90\end{array}$ & $\begin{array}{c}530.30 ; 530.40 ; 530.51 ; \\
530.82 ; 530.90 ;\end{array}$ \\
\hline 298 & $76 ; 98 ; 156 ; 221 ;$ & $76 ; 98 ; 156 ; 221 ; 221$ & $\begin{array}{c}530.30 ; 530.43 ; 530.62 \\
530.70\end{array}$ & $\begin{array}{c}530.30 ; 530.41 ; 530.52 \\
530.60 ; 530.70\end{array}$ \\
\hline
\end{tabular}


Table 6. Cont.

\begin{tabular}{|c|c|c|c|c|}
\hline Agent Id & Path Node Sequence & $\begin{array}{c}\text { Path Node Sequence } \\
\text { Reserved }\end{array}$ & Path Time Sequence & $\begin{array}{c}\text { Path Time Sequence } \\
\text { Reserved }\end{array}$ \\
\hline 320 & $1 ; 72 ; 381 ;$ & $1 ; 1 ; 72 ; 381 ;$ & $530.30 ; 530.49 ; 530.60$ & $\begin{array}{c}530.30 ; 530.40 ; 530.51 \\
530.60\end{array}$ \\
\hline 343 & $247 ; 263 ; 323 ; 116$; & $247 ; 263 ; 323 ; 116 ; 116$ & $\begin{array}{c}530.40 ; 530.54 ; 531.26 \\
531.40\end{array}$ & $\begin{array}{c}530.40 ; 530.52 ; 531.16 \\
530.30 ; 531.40\end{array}$ \\
\hline 375 & $68 ; 159 ; 188 ; 1 ;$ & $68 ; 159 ; 188 ; 1 ; 1 ;$ & $\begin{array}{c}530.50 ; 530.61 ; 530.97 \\
531.10\end{array}$ & $\begin{array}{c}530.50 ; 530.61 ; 530.90 \\
531.00 ; 531.10\end{array}$ \\
\hline 391 & $1 ; 72 ; 381 ;$ & $1 ; 1 ; 72 ; 381 ;$ & $530.50 ; 530.62 ; 530.80$ & $\begin{array}{c}530.50 ; 530.60 ; 530.71 \\
530.80\end{array}$ \\
\hline 428 & $470 ; 356 ; 299 ; 521 ;$ & $470 ; 470 ; 356 ; 299 ;$ 521; & $\begin{array}{c}530.60 ; 530.75 ; 531.14 \\
531.30\end{array}$ & $\begin{array}{c}530.60 ; 530.70 ; 530.83 \\
531.14 ; 531.30\end{array}$ \\
\hline 456 & $121 ; 19 ; 58 ;$ & $121 ; 19 ; 58 ; 58 ;$ & $530.60 ; 530.75 ; 530.90$ & $\begin{array}{c}530.60 ; 530.73 ; 530.87 \\
530.90\end{array}$ \\
\hline 479 & $1 ; 72 ; 381 ;$ & $1 ; 72 ; 381 ; 381 ;$ & 530.60; 530.75; 530.90; & $\begin{array}{c}530.60 ; 530.72 ; 530.87 \\
530.90\end{array}$ \\
\hline 553 & 521; 299; 356; 470; & 521; 299; 356; 470; 470; & $\begin{array}{c}530.70 ; 530.81 ; 531.20 \\
531.30\end{array}$ & $\begin{array}{c}530.70 ; 530.77 ; 531.07 \\
531.15 ; 531.30\end{array}$ \\
\hline 605 & $68 ; 159 ; 188 ; 1 ;$ & $68 ; 159 ; 188 ; 1 ; 1 ;$ & $\begin{array}{c}530.70 ; 530.86 ; 531.22 \\
531.40\end{array}$ & $\begin{array}{c}530.70 ; 530.86 ; 531.22 \\
531.40 ;\end{array}$ \\
\hline 721 & $1 ; 72 ; 381 ;$ & $1 ; 1 ; 72 ; 381 ;$ & 530.70; 530.88; 531.00; & $\begin{array}{c}530.70 ; 530.75 ; 530.90 \\
531.00 ;\end{array}$ \\
\hline 874 & $247 ; 263 ; 323 ; 116 ;$ & $247 ; 263 ; 323 ; 116 ; 116$ & $\begin{array}{c}530.80 ; 530.98 ; 531.70 \\
531.80\end{array}$ & $\begin{array}{c}530.80 ; 530.88 ; 531.68 \\
531.75 ; 531.80\end{array}$ \\
\hline 895 & $1 ; 72 ; 381 ;$ & $1 ; 1 ; 72 ; 381 ;$ & 530.90; 531.01; 531.10; & $\begin{array}{c}530.90 ; \text { 530.95; } 531.02 ; \\
531.10\end{array}$ \\
\hline 925 & $116 ; 323 ; 263 ; 247 ;$ & $116 ; 116 ; 323 ; 263 ; 247$ & $\begin{array}{c}531.00 ; 531.17 ; 531.89 \\
532.00\end{array}$ & $\begin{array}{c}531.00 ; 531.05 ; 531.19 \\
531.89 ; 532.00\end{array}$ \\
\hline 946 & $1 ; 72 ; 381 ;$ & $1 ; 1 ; 72 ; 381$ & 531.10; 531.27; 531.40; & $\begin{array}{c}531.10 ; 531.15 ; 531.30 \\
531.40\end{array}$ \\
\hline 987 & $121 ; 19 ; 58 ;$ & $121 ; 121 ; 19 ; 58 ;$ & $531.30 ; 531.40 ; 531.50$ & $\begin{array}{c}531.30 ; 531.35 ; 531.43 \\
531.50\end{array}$ \\
\hline
\end{tabular}

Table 7. Index comparisons between original case and reserved case.

\begin{tabular}{ccccccc}
\hline Network. & $\begin{array}{c}\text { Number of } \\
\text { Vehicles }\end{array}$ & $\begin{array}{c}\text { Average Distance } \\
\mathbf{( k m )}\end{array}$ & $\begin{array}{c}\text { Average Travel } \\
\text { Time (min) }\end{array}$ & $\begin{array}{c}\text { Average Speed } \\
\mathbf{( k m / h )}\end{array}$ & $\begin{array}{c}\text { Travel Time } \\
\text { Reduction }\end{array}$ \\
\hline Baseline & $1,260,907$ & 5.63 & 14.25 & 22.59 & - \\
\hline Reservation case $(5 \%)$ & $1,260,907$ & 5.63 & 12.97 & 24.82 & $9.0 \%$ \\
\hline Reservation case $(10 \%)$ & $1,260,907$ & 5.63 & 12.08 & 26.64 & $15.2 \%$ \\
\hline Reservation case $(15 \%)$ & $1,260,907$ & 5.63 & 10.83 & 29.71 & $24.0 \%$ \\
\hline
\end{tabular}

\section{Discussion}

There is specific analysis of the major congestion points. Figure 9 shows the inflow rate curve comparison after reservations at the mean bottleneck (links 49, 425, and 1028) in the Chicago network. The inflow rates of most congested bottlenecks are close to link capacity, and the delay and queues are significantly decreased after reservation. This can be measured as the shadow area rounded by inflow and capacity, which is shown to be Pareto-improving. The delay and queue are significantly decreased after reservation. 
Table 8 lists the comparison of link conditions between and after the reservation scheme. As shown, the link density of the major congested link is obviously decreased, and the ratio of inflow and capacity is closer to 1 .

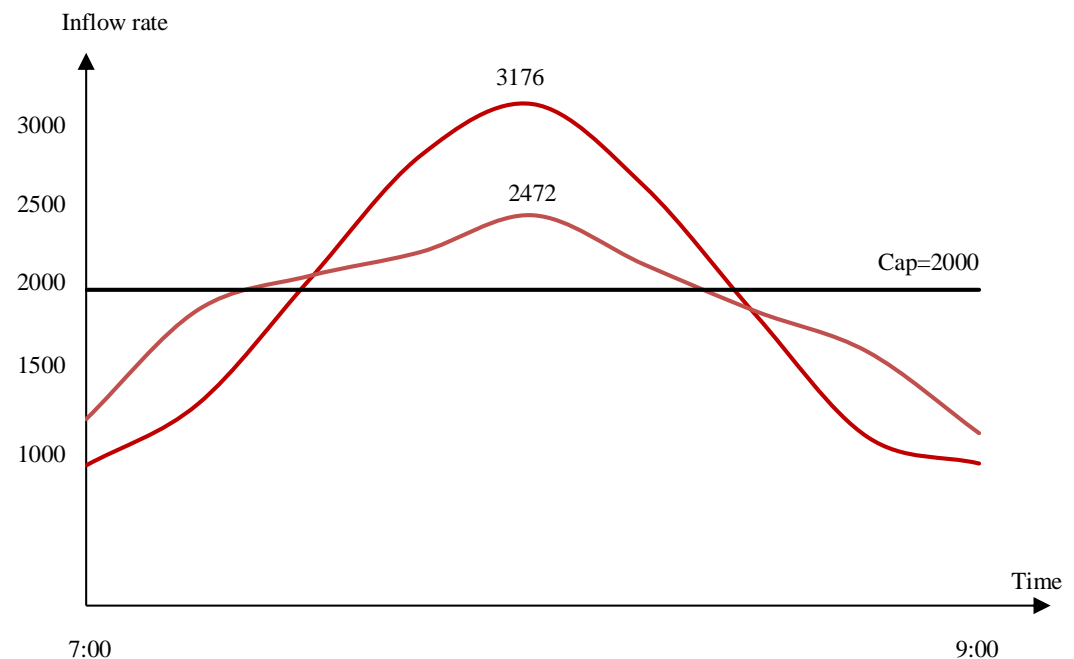

(a)

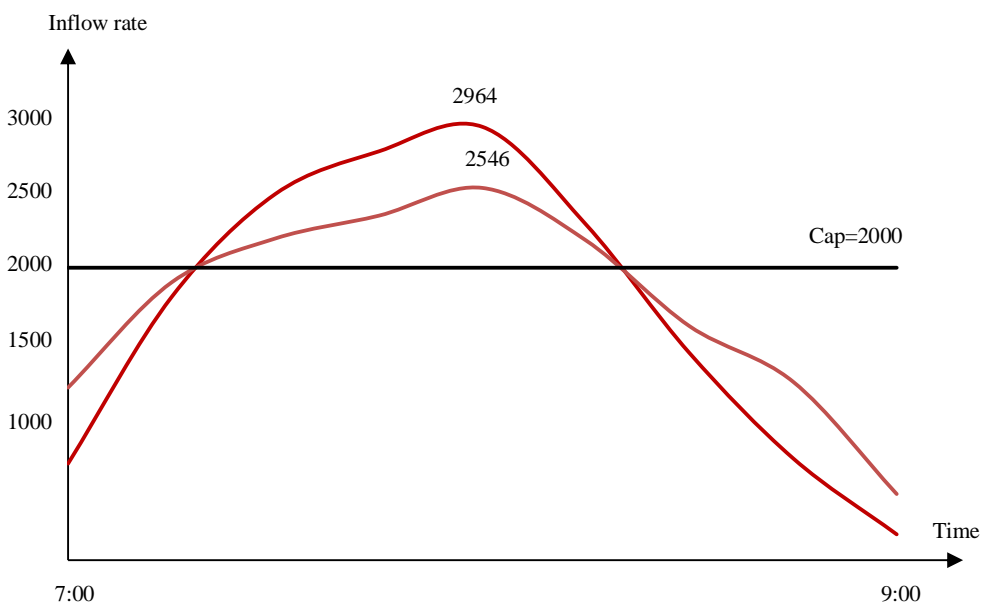

(b)

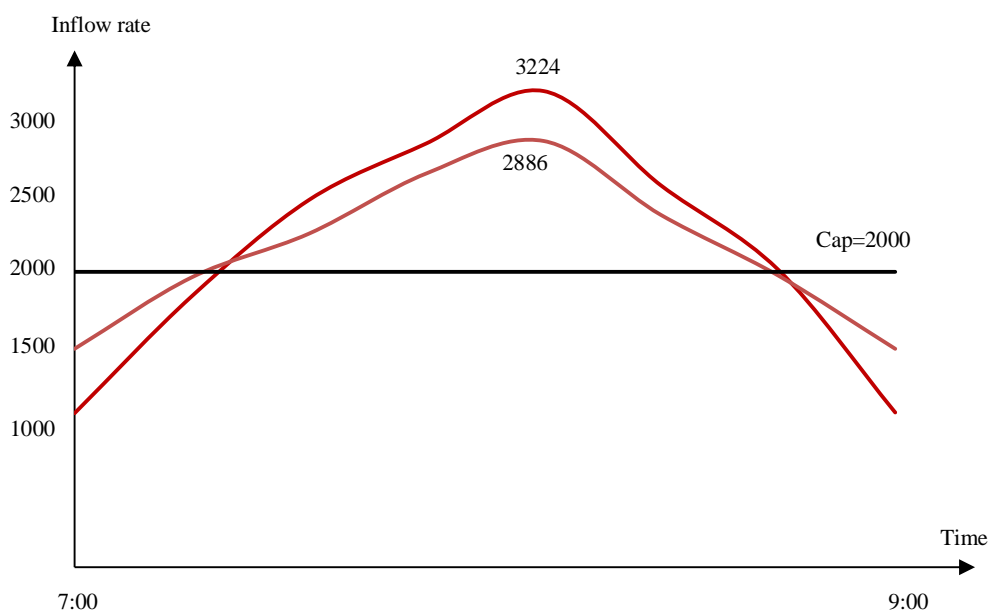

(c)

Figure 9. (a) Link 49 inflow/capacity curves before and after reservation; (b) link 425 inflow/capacity curves before and after reservation; (c) link 1028 inflow/capacity curves before and after reservation. 
Table 8. Link condition comparison before and after reservation.

\begin{tabular}{ccccc}
\hline Link Id & $\begin{array}{c}\text { Inflow }(\lambda) / \text { Capacity }(\mu) \text { Ratio } \\
\text { before Reservations }\end{array}$ & $\begin{array}{c}\text { Inflow }(\lambda) / \text { Capacity }(\mu) \text { Ratio } \\
\text { after Reservations }\end{array}$ & $\begin{array}{c}\text { Density before } \\
\text { Reservations }\end{array}$ & $\begin{array}{c}\text { Density after } \\
\text { Reservations }\end{array}$ \\
\hline 49 & $0.45 \leq \frac{\lambda}{\mu} \leq 1.61$ & $0.59 \leq \frac{\lambda}{\mu} \leq 1.38$ & 24.11 & 11.69 \\
425 & $0.36 \leq \frac{\lambda}{\mu} \leq 1.45$ & $0.56 \leq \frac{\lambda}{\mu} \leq 1.35$ & 32.23 & 26.52 \\
1028 & $0.52 \leq \frac{\lambda}{\mu} \leq 1.61$ & $0.66 \leq \frac{\lambda}{\mu} \leq 1.43$ & 29.87 & 20.15 \\
\hline
\end{tabular}

Figure 10 shows the link density, speed, and flow comparison among the major bottlenecks (links 49, 425, and 1028). The different depths of the figures indicate different values. In Figure $10 \mathrm{a}, \mathrm{b}$, the green area indicates that the road condition is frequent, and the red area indicates the road is congested. As shown in the figures, the road condition is much better after reservation. In Figure 10c, as the band width is smaller, the link flow is decreased during the same time period.
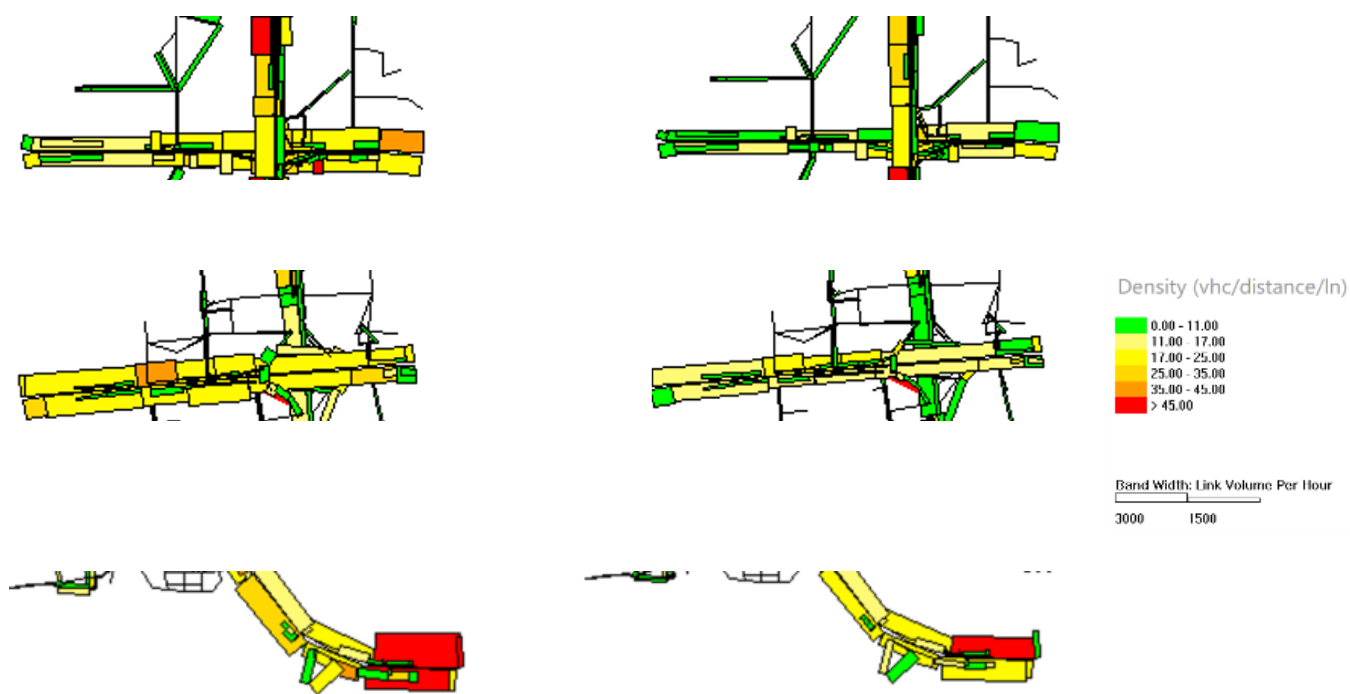

(a)
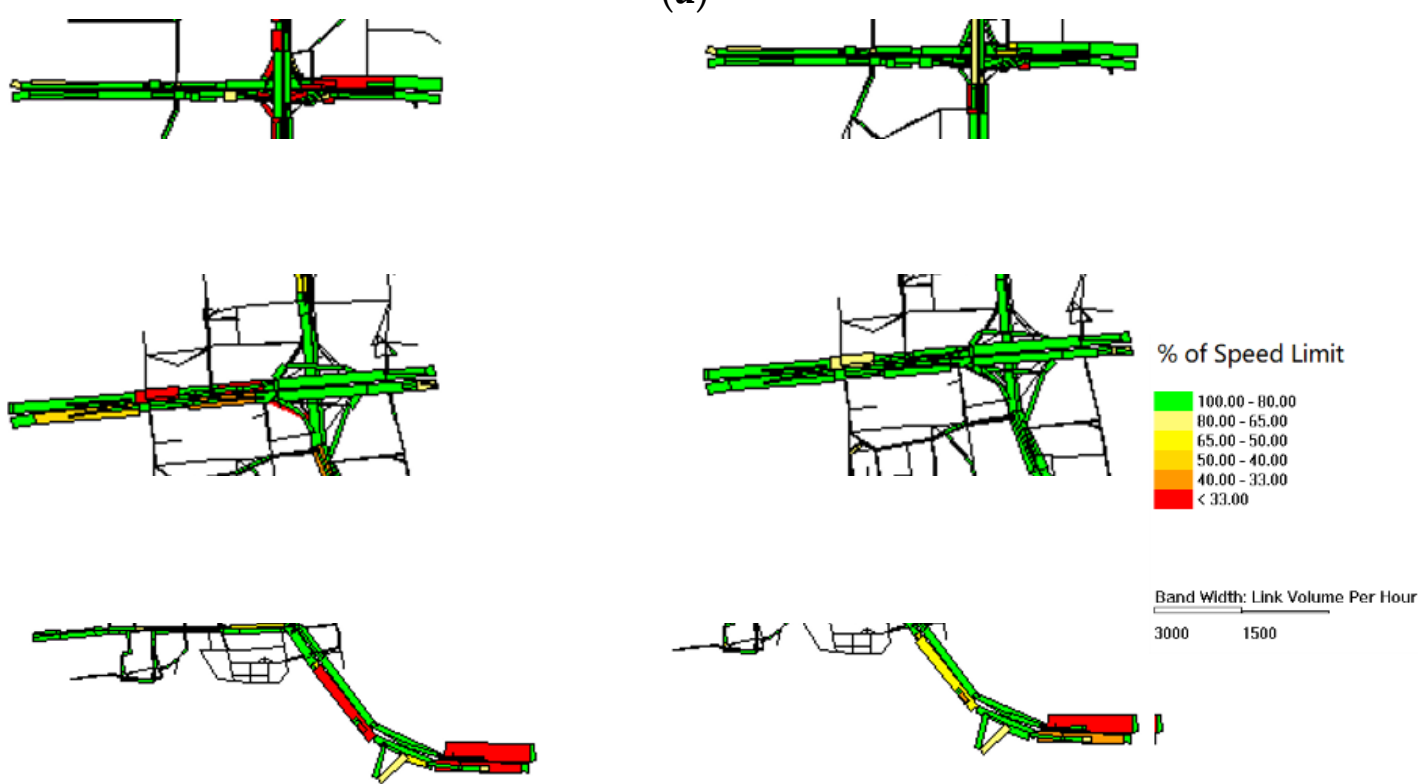

(b)

Figure 10. Cont. 

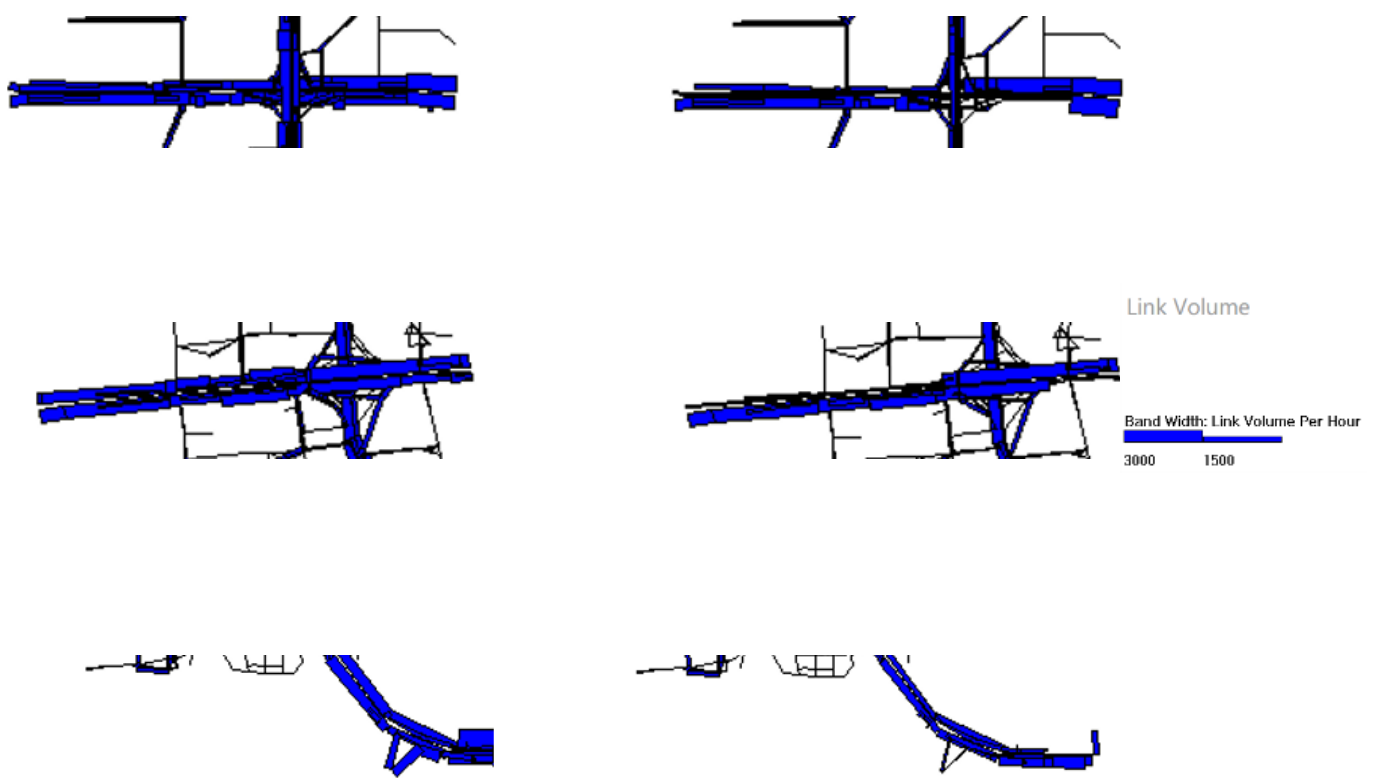

(c)

Figure 10. (a) Density comparison before and after reservation of links 49, 425, and 1028; (b) speed comparison before and after reservation of links 49,425, and 1028; (c) flow comparison before and after reservation of links 49, 425, and 1028 .

We would like to compare our proposed model to a closely related link-based system, the optimal dynamic traffic assignment (DTA) mathematical programming model proposed by Lasdon and Luo (1994). Table 9 lists the comparisons. In their model, the link capacity is fixed and its goal is to find a system optimal routing solution with fixed departure times based on the given exit function. Compared to this typical exit function-based DTA optimization model, our proposed agent-based model has the following unique features: (1) our agent-based reservation model provides a Pareto-improving solution for each user by embedding the complex end-to-end time window in the space-time network construct; (2) our scheduling problem is modeled using a timetabling problem with a space-time network representation; and (3) the users' departure times are intended to be flexible within a given time window to offer a system optimal solution that can control the variable capacity state. In future research, we will further extend the model to consider the minimum expected disutility of path travel times, as studied in the paper by Huang and Gao (2012).

Table 9. Comparison between traditional traffic flow model and our model.

\begin{tabular}{|c|c|c|}
\hline & $\begin{array}{l}\text { Traditional Traffic Model } \\
\text { (Lasdon and Luo, 1994) }\end{array}$ & Our Model \\
\hline Objective & $\begin{array}{c}\text { Travel time: } \\
\text { Obj=TT+pen } \times \sum_{j, t} q_{j t}+\sum_{j} d n_{j} \\
\text { pen: positive penalty coefficient } \\
q_{j t}: \text { number of vehicles unable to reach origin node } \mathrm{j} \text { at } \\
\text { time } \mathrm{t} \\
d n_{j}: \text { number of vehicles unable to arrive at destination } \\
\text { node } \mathrm{j} \text { over the whole time period }\end{array}$ & $\begin{array}{c}\text { Obj }=\sum_{a} \sum_{(i, j, t, s) \in S} c_{a}\left(i, j, t, t^{\prime}\right) \times x_{a}\left(i, j, t, t^{\prime}\right) \\
c_{a}\left(i, j, t, t^{\prime}\right): \text { cotts of space-time arc }\left(i, j, t, t^{\prime}\right) \text { for agent } a \\
x_{a}\left(i, j, t, t^{\prime}\right) \text { space-time arc choice of agent } a\end{array}$ \\
\hline
\end{tabular}


Table 9. Cont.

\begin{tabular}{|c|c|c|}
\hline & $\begin{array}{l}\text { Traditional Traffic Model } \\
\text { (Lasdon and Luo, 1994) }\end{array}$ & Our Model \\
\hline Constraints & 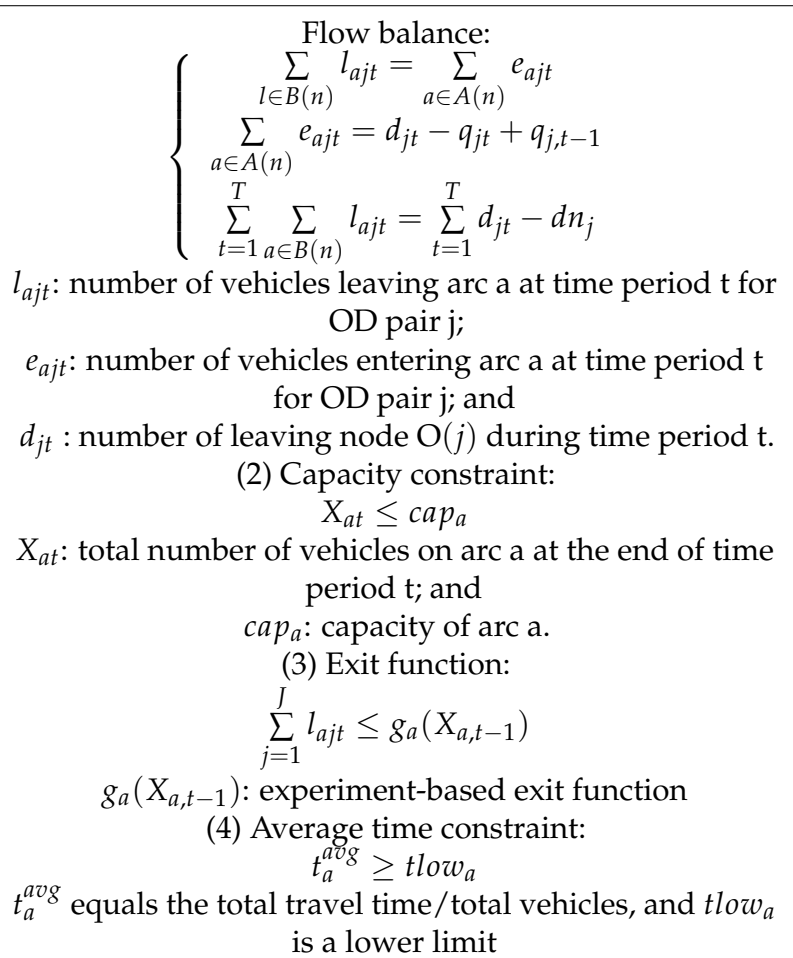 & $\begin{array}{c}\text { Flow balance: } \\
\sum_{j, t^{\prime}:\left(i, j, t, t^{\prime}\right) \in \beta^{O}(a)} x_{a}\left(i, j, t, t^{\prime}\right)=1 \quad \forall a, i=O(a), t=t_{0} \\
\sum_{i, t:\left(i, j, t, t^{\prime}\right) \in \beta^{D}(a)} x_{a}\left(i, j, t, t^{\prime}\right)=1 \quad \forall a, j=D(a), t^{\prime}=T \\
\sum_{i, t:\left(i, j, t, t^{\prime}\right) \in S} x_{a}\left(i, j, t, t^{\prime}\right)-\sum_{j^{\prime}, t^{\prime \prime}:\left(j, j^{\prime}, t^{\prime}, t^{\prime \prime}\right) \in S} x_{a}\left(i, j, t, t^{\prime}\right)= \\
0 \quad \forall a,\left(j, t^{\prime}\right) \in E /\left\{\left(O(a), t_{0}\right),(D(a), T)\right\} \\
\text { Link capacity: } \\
\sum_{a} x_{a}\left(i, j, t, t^{\prime}\right) \leq \operatorname{cap}(i, j), \forall t, t^{\prime} \in T \\
\text { Waiting cost setting: } \\
c_{a}\left(i, i, t, t^{\prime}\right) \leq \varepsilon, i \in\left\{\beta^{O}, \beta^{D}\right\}\end{array}$ \\
\hline
\end{tabular}

\section{Concluding Remarks}

This research proposes a new Pareto-improving reservation mechanism to provide an attractive travel timetable for each individual user. Through a set of illustrative and real-world examples, our proposed urban transportation network timetabling-based reservation system improves efficiency and sustainability by mitigating congestion. Compared with other single-criterion reservation applications that focus only on in-vehicle travel times or schedule delays, our new mobility service system highlights the benefits of controlling bottlenecks with different outflow rates. By utilizing the in-vehicle travel time window (which is defined by the origin departure time and destination arrival time) as the key control variable to be optimized, our proposed method offers a Pareto-improving reservation schedule for both the portion of users making reservations and other users with fixed departure time schedules. Through efficient user reservations for limited infrastructure resources, a number of numerical examples demonstrate reasonable performance improvements and potential.

Mathematically, we propose the presented integer programming model to minimize the end-to-end system travel costs within space-time constraints to solve the reservation timetable problem. The ADMM and DP methods are then applied to solve this problem in real-world applications. The developed heuristics algorithm is able to provide a systematic framework to obtain exact solutions.

In terms of the modeling framework, our proposed model has also captured some of the characteristics needed for the possible deployment of reservation systems in realworld settings. Specifically, compared with other standard space-time network model strategies (such as the accessibility-oriented network design problem described by Tong et al. (2015) [72] and the bounded rational behavior proposed by Liu and Zhou (2016) [64]), our research accomplishes the following: (1) it identifies users' actual departure and arrival time windows to form an efficient end-to-end timetable for a transportation network; and 
(2) it proposes a reservation system that offers a Pareto-improving reservation schedule for each agent.

In our future research, users' actual departure and arrival times can be determined by applying a deep learning strategy to multiple daily data sources to better reveal users' true preferences. One major study that we plan to undertake is to examine how the proposed model could be deployed and tested in practice in more controllable cases, such as parking area reservations and subway entrance flow quota reservations. In the future, when considering lane-changing behavior in a complex freeway system, we need to develop a sophisticated lane-based reservation scheme for autonomous vehicles. It is also very important to take into account and develop a demand-responsive reservation scheme for time-dependent travel demands when the system is oversaturated.

Author Contributions: Conceptualization, R.S. and L.S.; methodology, L.S.; software, L.S.; validation, R.S.; formal analysis, R.S.; investigation, L.S.; resources, R.S.; data curation, R.S.; writing-original draft preparation, L.S.; writing-review and editing, L.S.; visualization, L.S.; supervision, R.S.; project administration, R.S.; funding acquisition, R.S. All authors have read and agreed to the published version of the manuscript.

Funding: This research received no external funding.

Institutional Review Board Statement: Not applicable.

Informed Consent Statement: Not applicable.

Data Availability Statement: Not applicable.

Acknowledgments: We appreciate the many researchers in the Beijing Key Laboratory of Urban Traffic Operation Simulation and Decision Support, and the Beijing International Science and Technology Cooperation Base of Urban Transport. We also appreciate the corresponding researchers from the Beijing Transport Institute for providing some critical comments on our experiments. The first author wants to thank a number of scholars in this field, especially Shiwei He at Beijing Jiaotong University. The work presented in this paper remains the sole responsibility of the authors. This paper is supported by the National Natural Science Foundation of China (No. 62076023) and Research Project of China Railway Corporation (No. P2020X016).

Conflicts of Interest: The authors declare no conflict of interest.

\section{References}

1. $\quad$ Newell, G.F. Applications of Queueing Theory; Chapman and Hall Ltd.: New York, NY, USA, 1982.

2. Fosgerau, M.; Small, K.A. Hypercongestion in downtown metropolis. J. Urban Econ. 2013, 76, 122-134. [CrossRef]

3. Shang, P.; Li, R.; Guo, J.; Xian, K.; Zhou, X. Integrating Lagrangian and Eulerian observations for passenger flow state estimation in an urban rail transit network: A space-time-state hyper network-based assignment approach. Transp. Res. Part B Methodol. 2019, 121, 135-167. [CrossRef]

4. Mahmoudi, M.; Zhou, X. Finding optimal solutions for vehicle routing problem with pickup and delivery services with time windows: A dynamic programming approach based on state-space-time network representations. Transp. Res. Part B Methodol. 2016, 89, 19-42. [CrossRef]

5. Vickrey, W.S. Congestion theory and transport investment. Am. Econ. Rev. 1969, 59, 251-260.

6. Wang, X.; Yang, H. Bisection-based trial-and-error implementation of marginal cost pricing and tradable credit scheme. Transp. Res. Part B Methodol. 2012, 46, 1085-1096. [CrossRef]

7. Luo, Y.; Liu, J.; Lai, Q. Optimization of seat inventory allocation for passenger trains with first-come-first-serve seats. J. China Railw. Soc. 2016, 38, 1-5.

8. Liu, W.; Yang, H.; Yin, Y. Efficiency of a highway use reservation system for morning commute. Transp. Res. Part C Emerg. Technol. 2015, 56, 293-308. [CrossRef]

9. Levin, M.W.; Boyles, S.D.; Patel, R. Paradoxes of reservation-based intersection controls in traffic networks. Transp. Res. Part A 2016, 90, 14-25. [CrossRef]

10. Lamotte, R.; de Palma, A.; Geroliminis, N. On the use of reservation-based autonomous vehicles for demand management. Transp. Res. Part B Methodol. 2017, 99, 205-227. [CrossRef]

11. Xiong, C.; Shahabi, M.; Zhao, J.; Yin, Y.; Zhou, X.; Zhang, L. An integrated and personalized traveler information and incentive scheme for energy efficient mobility systems. Transp. Res. Part C Emerg. Technol. 2019, 38, 160-179. [CrossRef]

12. Levin, M.; Boyles, S.D. Intersection Auctions and Reservation-Based Control in Dynamic Traffic Assignment. Transp. Res. Rec. J. Transp. Res. Board 2015, 2497, 35-44. [CrossRef] 
13. Menelaou, C.; Kolios, P.; Timotheou, S.; Panayiotou, C.; Polycarpou, M. Controlling road congestion via a low-complexity route reservation approach. Transp. Res. Part C Emerg. Technol. 2017, 81, 118-136. [CrossRef]

14. Lioris, J.; Pedarsani, R.; Tascikaraoglu, F.Y.; Varaiya, P. Platoons of connected vehicles can double throughput in urban roads. Transp. Res. Part C Emerg. Technol. 2017, 77, 292-305. [CrossRef]

15. Zhou, W.; You, X.; Fan, W. A Mixed Integer Linear Programming Method for Simultaneous Multi-Periodic Train Timetabling and Routing on a High-Speed Rail Network. Sustainability 2020, 12, 1131. [CrossRef]

16. Wu, J.; Liu, M.; Sun, H.; Li, T.; Gao, Z.; Wang, D.Z.W. Equity-based timetable synchronization optimization in urban subway network. Transp. Res. Part C Emerg. Technol. 2014, 51, 1-18. [CrossRef]

17. Guo, Y.; Ma, J.; Xiong, C.; Li, X.; Zhou, F.; Hao, W. Joint optimization of vehicle trajectories and intersection controllers with connected automated vehicles: Combined dynamic programming and shooting heuristic approach. Transp. Res. Part C Emerg. Technol. 2018, 98, 54-72. [CrossRef]

18. Daganzo, C.F.; Garcia, R.C. A Pareto Improving Strategy for the Time-Dependent Morning Commute Problem. Transp. Sci. 2000, 34, 303-311. [CrossRef]

19. Daganzo, C.F. A Pareto optimum congestion reduction scheme. Transp. Res. Part B Methodol. 2008, 29, 139-154. [CrossRef]

20. Chen, L.; Yang, H. Managing congestion and emissions in road networks with tolls and rebates. Transp. Res. Part B 2012, 46, 933-948. [CrossRef]

21. Guo, X.; Yang, H. Pareto-improving congestion pricing and revenue refunding with multiple user classes. Transp. Res. Part $B$ Methodol. 2010, 44, 972-982. [CrossRef]

22. Barthelemy, J.; Carletti, T. A dynamic behavioral traffic assignment model with strategic agents. Transp. Res. Part C Emerg. Technol. 2017, 85, 23-46. [CrossRef]

23. Chen, X.; Zhang, W.; Guo, X.; Liu, Z.; Wang, S. An improved learning-and-optimization train fare design method for addressing commuting congestion at CBD stations. Transp. Res. Part E Logist. Transp. Rev. 2021, 153, 102427. [CrossRef]

24. Dimitris, B.; Arthur, D.; Sebastien, M. Existence of urban-scale macroscopic fundamental diagrams: Some experimental findings. Proc. Natl. Acad. Sci. USA 2019, 116, 5943-5948.

25. Tian, Q.; Huang, H.-J.; Yang, H.; Gao, Z. Efficiency and equity of ramp control and capacity allocation mechanisms in a freeway corridor. Transp. Res. Part C Emerg. Technol. 2012, 20, 126-143. [CrossRef]

26. Meng, Q.; Khoo, H.L. A Pareto-optimization approach for a fair ramp metering. Transp. Res. Part C Emerg. Technol. 2009, 18, 489-506. [CrossRef]

27. Xiong, C.; Zhang, L. Positive Model of Departure Time Choice under Road Pricing and Uncertainty. Transp. Res. Rec. J. Transp. Res. Board 2013, 2345, 117-125. [CrossRef]

28. Xiong, C.; Chen, X.; He, X.; Lin, X.; Zhang, L. Agent-based en-route diversion: Dynamic behavioral responses and network performance represented by Macroscopic Fundamental Diagrams. Transp. Res. Part C Emerg. Technol. 2015, 64, 148-163. [CrossRef]

29. Zou, M.; Li, M.; Lin, X.; Xiong, C.; Mao, C.; Wan, C.; Zhang, K.; Yu, J. An agent-based choice model for travel mode and departure time and its case study in Beijing. Transp. Res. Part C Emerg. Technol. 2015, 64, 133-147. [CrossRef]

30. Wang, Y.; Correia, G.H.D.A.; van Arem, B.; Timmermans, H.H. Understanding travellers' preferences for different types of trip destination based on mobile internet usage data. Transp. Res. Part C Emerg. Technol. 2018, 90, 247-259. [CrossRef]

31. Chiariotti, F.; Pielli, C.; Zanella, A.; Zorzi, M. A Dynamic Approach to Rebalancing Bike-Sharing Systems. Sensors 2018, $18,512$. [CrossRef]

32. Wang, H.; Cheu, R. Operations of a Taxi Fleet for Advance Reservations Using Electric Vehicles and Charging Stations. Transp. Res. Rec. J. Transp. Res. Board 2013, 2352, 1-10. [CrossRef]

33. Han, Z.; Chen, Y.; Li, H.; Zhang, K.; Sun, J. Customized Bus Network Design Based on Individual Reservation Demands. Sustainability 2019, 11, 5535. [CrossRef]

34. Wang, X.; Wang, X. Flexible parking reservation system and pricing: A continuum approximation approach. Transp. Res. Part $B$ Methodol. 2019, 128, 408-434. [CrossRef]

35. Liu, W.; Yang, H.; Yin, Y. Expirable parking reservations for managing morning commute with parking space constraints. Transp. Res. Part C Emerg. Technol. 2014, 44, 185-201. [CrossRef]

36. Tong, L.; Zhou, L.; Liu, J.; Zhou, X. Customized bus service design for jointly optimizing passenger-to-vehicle assignment and vehicle routing. Transp. Res. Part C Emerg. Technol. 2017, 85, 451-475. [CrossRef]

37. Inaba, K.; Shibui, M.; Naganawa, T.; Ogiwara, M.; Yoshikai, N. Intelligent parking reservation service on the Internet. In Proceedings of the 2001 Symposium on Applications and the Internet Workshops, San Diego, CA, USA, 8-12 January 2001. [CrossRef]

38. Hanif, N.H.H.M.; Badiozaman, M.H.; Daud, H. Smart parking reservation system using short message services (SMS). In Proceedings of the 2010 International Conference on Intelligent and Advanced Systems, Manila, Philippines, 15-17 June 2010; pp. 1-5. [CrossRef]

39. Tsai, M.-T.; Chu, C.-P. Evaluating parking reservation policy in urban areas: An environmental perspective. Transp. Res. Part D Transp. Environ. 2012, 17, 145-148. [CrossRef]

40. Kaspi, M.; Raviv, T.; Tzur, M. Parking reservation policies in one-way vehicle sharing systems. Transp. Res. Part B Methodol. 2014, 62, 35-50. [CrossRef] 
41. Lei, C.; Ouyang, Y. Dynamic pricing and reservation for intelligent urban parking management. Transp. Res. Part C Emerg. Technol. 2017, 77, 226-244. [CrossRef]

42. Latinopoulos, C.; Sivakumar, A.; Polak, J. Response of electric vehicle drivers to dynamic pricing of parking and charging services: Risky choice in early reservations. Transp. Res. Part C Emerg. Technol. 2017, 80, 175-189. [CrossRef]

43. Reynolds, W.L.; Zhou, X.; Rouphail, N.M.; Li, M. Estimating Sustained Service Rates at Signalized Intersections with Short Left-Turn Pockets. Transp. Res. Rec. J. Transp. Res. Board 2010, 2173, 64-71. [CrossRef]

44. Dresner, K.; Stone, P. Multiagent traffic management: A reservation-based intersection control mechanism. In Proceedings of the Third International Joint Conference on Autonomous Agents and Multiagent Systems, New York, NY, USA, 19-23 July 2004; Volume 2, pp. 530-537.

45. Yu, C.; Sun, W.; Liu, H.X.; Yang, X. Managing connected and automated vehicles at isolated intersections: From reservation- to optimization-based methods. Transp. Res. Part B Methodol. 2019, 122, 416-435. [CrossRef]

46. Ma, J.; Li, X.; Zhou, F.; Hao, W. Designing optimal autonomous vehicle sharing and reservation systems: A linear programming approach. Transp. Res. Part C Emerg. Technol. 2017, 84, 124-141. [CrossRef]

47. Guo, Q.W.; Chow, J.Y.; Schonfeld, P. Stochastic dynamic switching in fixed and flexible transit services as market entry-exit real options. Transp. Res. Part C Emerg. Technol. 2017, 23, 380-399. [CrossRef]

48. Geroliminis, N.; Daganzo, C.F. Existence of urban-scale macroscopic fundamental diagrams: Some experimental findings. Transp. Res. Part B Methodol. 2008, 42, 759-770. [CrossRef]

49. Qian, Z.; Li, J.; Li, X.; Zhang, M.; Wang, H. Modeling heterogeneous traffic flow: A pragmatic approach. Transp. Res. Part B Methodol. 2017, 99, 183-204. [CrossRef]

50. Kometani, E.; Sasaki, T. A Safety Index for Traffic with Linear Spacing. Oper. Res. 1959, 7, 704-720. [CrossRef]

51. Levin, M.; Boyles, S.D. A cell transmission model for dynamic lane reversal with autonomous vehicles. Transp. Res. Part C Emerg. Technol. 2016, 68, 126-143. [CrossRef]

52. Ukkusuri, S.V.; Han, L.; Doan, K. Dynamic user equilibrium with a path based cell transmission model for general traffic networks Transp. Res. Part B Methodol. 2012, 46, 1657-1684. [CrossRef]

53. Wei, Y.; Avc1, C.; Liu, J.; Belezamo, B.; Aydin, N.; Li, P.; Zhou, X. Dynamic programming-based multi-vehicle longitudinal trajectory optimization with simplified car following models. Transp. Res. Part B Methodol. 2017, 106, 102-129. [CrossRef]

54. Newell, G. A simplified car-following theory: A lower order model. Transp. Res. Part B Methodol. 2002, 36, 195-205. [CrossRef]

55. Ouyang, Y.; Yang, H.; Daganzo, C.F. Performance of reservation-based carpooling services under detour and waiting time restrictions. Transp. Res. Part B Methodol. 2021, 150, 370-385. [CrossRef]

56. Ma, J.; Smith, B.L.; Zhou, X. Personalized real-time traffic information provision: Agent-based optimization model and solution framework. Transp. Res. Part C Emerg. Technol. 2015, 64, 164-182. [CrossRef]

57. Boyac1, B.; Zografos, K.; Geroliminis, N. An integrated optimization-simulation framework for vehicle and personnel relocations of electric carsharing systems with reservations. Transp. Res. Part B Methodol. 2017, 95, 214-237. [CrossRef]

58. Molnar, G.; Homem, D. Long-term vehicle reservations in one-way free-floating carsharing systems: A variable quality of service model. Transp. Res. Part C Emerg. Technol. 2019, 98, 298-322. [CrossRef]

59. Repoux, M.; Kaspi, M.; Boyac1, B.; Geroliminis, N. Dynamic prediction-based relocation policies in one-way station-based carsharing systems with complete journey reservations. Transp. Res. Part B Methodol. 2019, 130, 82-104. [CrossRef]

60. Wang, S.; Li, Z.; Nie, X. A reservation and allocation model for shared-parking addressing the uncertainty in drivers' arrival/departure time. Transp. Res. Part C Emerg. Technol. 2021, 135, 103484. [CrossRef]

61. Levin, M.W.; Boyles, S.D. A multiclass cell transmission model for shared human and autonomous vehicle roads. Transp. Res. Part C Emerg. Technol. 2016, 62, 103-116. [CrossRef]

62. Cheng, Q.; Chen, Y.; Liu, Z. A bi-level programming model for the optimal lane reservation problem. Expert Syst. Appl. 2021, 189, 116147. [CrossRef]

63. Jia, A.; Zhou, X.; Li, M.; Rouphail, N.; Williams, B. Incorporating stochastic road capacity into day-to-day traffic simulation and traveler learning framework: Model development and case study. Transp. Res. Rec. J. Transp. Res. Board 2011, 2254, 112-121. [CrossRef]

64. Liu, J.; Zhou, X. Capacitated transit service network design with boundedly rational agents. Transp. Res. Part B Methodol. 2016, 93, 225-250. [CrossRef]

65. Meng, L.; Zhou, X. Modeling benefit of simultaneous train rerouting and rescheduling on an n-track network. Transp. Res. Part B 2014, 67, 208-234. [CrossRef]

66. Liao, F. Modeling duration choice in space-time multi-state supernetworks for individual activity-travel scheduling. Transp. Res. Part C Emerg. Technol. 2016, 69, 16-35. [CrossRef]

67. Lasdon, L.S.; Luo, S. Computational experiments with a system optimal dynamic traffic assignment model. Transp. Res. Part C Emerg. Technol. 1994, 2, 109-127. [CrossRef]

68. Huang, H.; Gao, S. Optimal paths in dynamic networks with dependent random link travel times. Transp. Res. Part B Methodol. 2012, 46, 579-598. [CrossRef]

69. Luh, P.B.; Hoitomt, D.J.; Max, E.; Pattipati, K.R. Parallel machine scheduling using Lagrangian relaxation. In Proceedings of the IEEE International Conference on Computer Integrated Manufacturing, Troy, NY, USA, 23-25 May 1988; pp. $244-248$. 
70. Mahmassani, H.S.; Jayakrishnan, R. System performance and user response under real-time information in a congested traffic corridor. Transp. Res. Part A Gen. 1991, 25, 293-307. [CrossRef]

71. Cherkassky, B.V.; Goldberg, A.V.; Radzik, T. Shortest paths algorithms: Theory and experimental evaluation. Math. Program. 1996, 73, 129-174. [CrossRef]

72. Tong, L.; Zhou, X.; Miller, H. Transportation network design for maximizing space-time accessibility. Transp. Res. Part B Methodol. 2015, 81, 555-576. [CrossRef] 